\title{
Chemically/Electrically-assisted Regeneration of Polyacrylonitrile-based Hydrogel Adsorbed Heavy Metals
}

\author{
Amany A. El Mansoub \\ National Research Centre \\ Marwa El-Sayed ( $\nabla$ eng_marwa06@yahoo.com ) \\ National Research Center Egypt https://orcid.org/0000-0001-7812-5952 \\ Rasha M. El Nashar \\ CU Faculty of Science: Cairo University Faculty of Science \\ Hussein M. Fahmy \\ Cairo University Faculty of Science \\ Abdelghani M.G. Abulnour \\ National Research Centre
}

\section{Research Article}

Keywords: Hydrogel, heavy metals, adsorption, isotherms, kinetics, electrically-assisted regeneration

Posted Date: February 22nd, 2021

DOI: https://doi.org/10.21203/rs.3.rs-213843/v1

License: (c) (i) This work is licensed under a Creative Commons Attribution 4.0 International License. Read Full License 


\title{
Chemically/Electrically-Assisted Regeneration of Polyacrylonitrile- based Hydrogel adsorbed Heavy Metals
}

\author{
Amany A. El Mansoub ${ }^{(1)}$, Marwa M. El Sayed* (1), Rasha M. El Nashar ${ }^{(2)}$, Hussein M. \\ Fahmy $^{(2)}$, and Abdelghani M.G. Abulnour ${ }^{(1)}$ \\ (1) Chemical Engineering and Pilot Plant Department, National Research Center, Cairo, Egypt El- \\ Bohouth Street, Dokki; P.O. Box 12622 Phone: +201096170061, Fax: +20-2-3370931 \\ (2) Chemistry Department, Faculty of Science, Cairo University, Egypt \\ *corresponding author email:[ dr.marwameid@gmail.com]
}




\title{
Chemically/Electrically-Assisted Regeneration of Polyacrylonitrile- based Hydrogel adsorbed Heavy Metals
}

\author{
Amany A. El Mansoub (1), Marwa M. El Sayed ${ }^{(1)}$, Rasha M. El Nashar ${ }^{(2)}$, Hussein M. \\ Fahmy ${ }^{(2)}$, and Abdelghani M.G. Abulnour ${ }^{(1)}$ \\ (3) Pilot Plant \& Chemical Engineering Department, Engineering Research Division, \\ National Research Center, Egypt \\ (4) Chemistry Department, Faculty of Science, Cairo University, Egypt
}

\begin{abstract}
Adsorption is an important technology for the removal of heavy metals from industrial effluents. Efficient regeneration of exhausted adsorbents is essential for improving the applicability of different adsorbents. In this work an adsorptive polyacrylonitrile-based hydrogel was characterized and investigated in terms of adsorption/regeneration using both conventional chemical and electrical-assisted regeneration techniques. The hydrogel characterization includes FTIR, XRD, SEM, EDAX, porosity, and electrical conductivity. Hydrogel performance in adsorption and conventional chemical regeneration was tested. Further, electrically-assisted regeneration using a specially designed cell was also investigated.

The maximum adsorption capacities for chromium and nickel were 8.082, and 17.437 $\mathrm{mg} / \mathrm{g}$, respectively. The isotherm data fitted Freundlich, while kinetic data fitted pseudo-secondorder model.

Conventional chemical desorption showed regeneration efficiency of 15.58 , and $27.27 \%$ for chromium and nickel, respectively. While, the electrically-assisted regeneration showed much higher values of 51.6, and $98.3 \%$ for chromium and nickel, respectively indicating the merit of using electrically-assisted chemical regeneration for enhancing heavy metals adsorbing hydrogel applicability.
\end{abstract}

\section{KEYWORDS}

Hydrogel, heavy metals, adsorption, isotherms, kinetics, electrically-assisted regeneration. 


\section{Introduction}

A material can be considered as a hydrogel when water constitutes around $10 \%$ of its weight or its volume. The existence of hydrophilic groups in the hydrogel network such as $\left(-\mathrm{NH}_{2}\right.$, $-\mathrm{COOH},-\mathrm{OH},-\mathrm{CONH}_{2}$, - $\mathrm{CONH}$, and $\left.-\mathrm{SO}_{3} \mathrm{H}\right)$ is the main reason for their hydrophilicity. The hydrogel building blocks specific functional groups can be changed to regulate the affinity of hydrogels to various target pollutants [1], [2]. There is a huge progress in hydrogel's science development leading to smart hydrogels which describe the use of polymeric matrixes hydrogels blended with functional additives to enhance their properties [3].

Conducting polymer hydrogels can be synthesized through polymerizing a conductive polymer with a non-conducting hydrogel matrix chemically or using electrochemical polymerization synthesis techniques. Electro-conductive hydrogels (ECHs) with their electrically high permittivity consist primarily of a naturally conductive polymer grafted with a threedimensional cross-linked network hydrogel. This provides a suitable blend for the high conductivity of electro-active polymers (EAPs) and the ability of the hydrogel to swell/de-swell. There are various types of EAPs that can be used as conducting polymers, such as polypyrrole (PPY), polyaniline (PAni), and poly (3,4-ethylenedioxythiophene) (PEDOT) [4].

Many electro conductive polymers (ECPs) networked polymer / substrates are reported such as Polyacrylic acid [5], Polyvinyl alcohol [6], and cellulose [7]) in combination with PPY, Alg: alginate [8], PU: polyurethane [9], and PEG: poly(ethylene glycol) [10] for PEDOT, heparin [11], PEGDA: poly (ethylene glycol) diacrylate [12], and PAAM: polyacrylamide [13]. Among conductive hydrogels, PAni has gained a great deal of interest in a wide range of applications as an electro-active polymer. Multi-functional PAni hydrogel synthesis with good electrical conductivity, high surface area and three-dimensional porous nanostructures is reported [4], [14].

Heavy metals removal has proven to be crucial to minimize the risk of their uptake by plants, animal and humans [15], [16]. The commonly known removal/remediation process are considered to be expensive due to the use of high cost non-regenerable materials [17]. The most popular technological methods for the removal of metal ions from industrial wastewater, in

particular wastewater electroplating, includes precipitation, adsorption, ion-exchange, electrochemical, biological, water treatment technologies using membrane, photocatalysis process and nanotechnology [15], [16], [18] . In addition, hydrogel based adsorption membranes are 
offering a dual function of filtration and adsorption for the removal of trace amounts of pollutants [19].

Many adsorbents were reported recently, including: commercial adsorbents, bio adsorbents, clays, activated carbons, zeolites, metal oxides, coal fly ash, rice husk ash, nano material and conducting polymer to remove heavy metals from polluted water [17], [20], [21]. In addition, heavy metal accumulation could happen with a numerous organic and inorganic matters, mostly organic compounds [22]. Adsorbents can be categorized as (natural materials, manufacturing by-products, agricultural, biological waste, biopolymers, and hydrogels) [23]. Different hydrogel composites and blends have been studied in terms of mechanical and swelling properties for heavy metals removal such as conductive polymers as (PAni and PPY) with the PAN composites, PVA with PAN blend and PVA with PAni as a conductive hydrogel [14], [24][26].

Hydrogels application for the removal of dye and heavy metal ions, with their excellent adsorption ability, high functionality, wettability, reusability and non-toxicity, have rendered them good candidates for removal of toxic aquatic pollutants. In addition, some modifications during the hydrogel synthesis to be customized in terms of accommodate different operating factors, such as temperature, $\mathrm{pH}$ and ion power, have added an advantage for their use in wastewater treatment [27].

Desorption/regeneration of adsorbents in the elimination of heavy metal ions is one of the main aspects of water treatment technologies via controlling its economy [28]. The heavy metal ions desorption from sorbent and sorbents is called regeneration. Desorption behavior is clarified by the solid and liquid $(\mathrm{S} / \mathrm{L})$ ratio, where the solid phase is the adsorbent caring for heavy metal ions and the liquid phase is the desorbing eluent [29]. The commonly used desorption techniques include thermal, ultrasonic, chemical, and electrochemical [30].

Regenerating agents, as (acids, alkalis, salts, deionized water, chelating agents, and buffer solutions) are used in various studies, which help in determining the applicability of a adsorbents [28]. These agents should be safe, inexpensive, and simple to prepare and manage, thus, the most acids and/or bases are commonly used [31].

Reusable hydrogel should have two essential criteria which are reversible adsorption and hydrogel stability. The hydrogel should be mechanically, chemically and biologically stable through successive adsorption and desorption cycles. Awareness of the chemical, thermal and 
mechanical resistance of the hydrogel helps to determine the range of suitable operating conditions [31]. Reusability is among the most important hydrogel characteristics for its applications; however, it is a problem for traditional hydrogels due to the lack of mechanical strength after swelling in water [32].

The enhancement of chemical desorption techniques via using electricity in various ways led to introduction of electrical enhancement fundamentally and at the adsorption and desorption. The electrochemical treatment of industrial wastewater provided a significant development for the reduction of the heavy metal ions through redox reaction at cathodic electrode for metals present in wastewater [18].

Parameters influencing the efficiency of electrochemical processes can be categorized, to cover design parameters (e.g. electrode material, electrode spacing, electrode's arrangement, electrode shape, power supply type, and EC reactor mode) and operational parameters (such as current density, applied voltage, working time and temperature, solution $\mathrm{pH}$, and initial salt concentration) [33].

The aim of the current work is to identify the applicability of electrically-assisted regeneration of polyacrylonitrile-based hydrogel, applied for heavy metals adsorption from aqueous solutions to enhance its efficiency as compared to chemical regeneration.

\section{Materials and methods}

\subsection{Materials}

A polyacrylonitrile-based hydrogel (PAN-based HG) has been provided by HF Pilot (National Research Centre) group with three basic polymers: PAN, polyvinyl alcohol (PVA), and PAni, through specific operating conditions. Briefly, starting with PAN alkaline hydrolysis, mixing of soluble PAN, and PVA followed by blending with PAni then crosslinking followed by filtration, washing, drying. The PAN-based $\mathrm{HG}$ as previously described but at different interaction conditions (crosslinker amount, and washing step) [34]. Adsorbents chromium nitrate (PANREAC QUIMICA, Barcelona, Spain) and nickel sulfate (ARABLAB, Dubai, UAE) as sources for $\mathrm{Cr}^{3+}$ and $\mathrm{Ni}^{2+}$ metal ions. The $\mathrm{pH}$ was modified with either hydrochloric acid or sodium carbonate (ADWIC, Egypt). Hydrochloric acid as a regenerating solution (ADWIC, Egypt). Whatman filter paper no. 4 was used for filtration. 


\subsection{Methods}

\subsubsection{Hydrogel characterization}

Infrared spectrum (FTIR) was processed using (FT/IR-6100typeA, Jasco, Japan) with databases as TGS detection and absorbance technology ranging around 399.193-4000.6 $\mathrm{cm}^{-1}, 2$ $\mathrm{mm} / \mathrm{sec}$ scan rate, $4 \mathrm{~cm}^{-1}$ resolutions and $10000 \mathrm{~Hz}$ filter. Defining the structure of the PANbased hydrogel using X-Ray Diffract meter (XRD) device (EMPYREAN, DY 1007, Netherlands) at a temperature of $25{ }^{\circ} \mathrm{C}$, using the $\mathrm{Cu}$ anode material of $30 \mathrm{~mA}$, the $45 \mathrm{kV}$ generator adjustments and the [ $\left.{ }^{\circ} 2 \mathrm{Theta}\right]$ location from 4.0150 to 79.9610 . The morphology of the PAN-based hydrogel was analyzed using the Scanning Electron Microscope (SEM) and its Energy X-Ray Spectroscopy (EDX) data for surface elemental composition identification (QUANTA FEG 250, European Union at $20 \mathrm{KV}$ assessments). The specific surface area and average pore size identification were calculated using the Brunauer-Emmett-Teller (BET) assessment model (PEL Sorb Max, Japan). Measurement of electrical conductivity for the PANbased hydrogel was performed using dielectric, conductivity and impedance spectrometers (NovoControl Co., Germany) based on observable BDS technology coupled with the Quatro Cryosystem, with data obtained at ambient temperature, and frequency range $3 \mathrm{uHz}$ to $20 \mathrm{MHz}$, and the conductivity has been estimated by [35] the following equation (1).

$$
\text { Electrical conductivity }(\sigma)=\ln 2 \frac{\left(\frac{V}{I}\right)}{\pi t}
$$

Where: $(\sigma)$ is the sample static electrical conductivity $(\mathrm{S} / \mathrm{cm}),(\mathrm{V})$ is the applied voltage (v), (I) is the measured current (A) and (t) is the thickness of sample disk (1 mm approximately).

$0.5 \mathrm{~g}$ of the dry PAN-based HG soaked in $0.5 \mathrm{~L}$ water distilled for $24 \mathrm{~h}$ and filtered using Whitman filter paper to eliminate extra surface water were used for swelling water ratio (SWR) calculation. Before and after the swelling, the swollen hydrogel was assessed. SWR has been determined [36] using the following equation (2): 


$$
\text { Swelling Water Ratio }(S W R)=\frac{\left(W_{s}-W_{d}\right)}{W_{d}}
$$

Where: (SWR) is the amount of absorbed water per the amount of dry hydrogel sample $(\mathrm{g} / \mathrm{g}),(\mathrm{Ws})$ is the weight of the swollen sample $(\mathrm{g})$ and $\left(\mathrm{W}_{\mathrm{d}}\right)$ is the weight of the dry sample $(\mathrm{g})$.

\subsubsection{Adsorption}

The improved adsorptive properties of PAN-based HG have been examined onto the adsorption tests to study their ability of removing heavy metals (chromium, and nickel) from synthetic wastewater to be applied later for wastewater treatment applications.

The ions adsorption potential has been assessed using batch balance technique, where $1 \mathrm{~g}$ of pre-swollen hydrogel was added to $1 \mathrm{~L}$ of a specific concentration of the salt solution in a suitable flask. The flask was shaken using a shaker (SCILOGEX SK-O330-Pro, USA) for ( $3 \mathrm{~h}$ ) at ambient temperature followed by filtration using filter paper. The concentration of $\mathrm{Cr}^{3+}$ and $\mathrm{Ni}^{2+}$ in solution can then be calculated using FAA spectrometry.

The performance of the adsorptive PAN-based HG towards the tested heavy metals $\left(\mathrm{Cr}^{3+}\right.$ and $\mathrm{Ni}^{2+}$ ), has been optimized in the authors' previous work [34] in terms of adsorption factors including $\mathrm{pH}$, time, metal concentration. The adsorption potential $\left(\mathrm{q}_{\mathrm{e}}\right)$ and the heavy metal removal percentage ( $\mathrm{R} \%$ ) were calculated using the following equations (3) and (4):

$$
\text { Adsorption capacity }\left(Q_{e}\right)=\frac{\left(C_{0}-C_{e}\right) V}{m}
$$

Where: $\left(\mathrm{Q}_{\mathrm{e}}\right)$ is the equilibrium adsorption capacity $(\mathrm{mg} / \mathrm{g}),\left(\mathrm{C}_{0}\right)$ is the initial salt concentration $(\mathrm{mg} / \mathrm{L}),\left(\mathrm{C}_{\mathrm{e}}\right)$ is the salt concentration in the solution after the adsorption $(\mathrm{mg} / \mathrm{L})$, $(\mathrm{V})$ is the solution volume $(\mathrm{L})$ and $(\mathrm{m})$ is the amount of hydrogel used $(\mathrm{g})$.

$$
\text { Adsorption (A) \%= } \frac{\left(C_{0}-C_{e}\right)}{C_{0}} 100
$$

\subsubsection{Regeneration}

After the adsorption process, the resulting PAN-based HG are saturated with heavy metals, thus its regeneration chemically and electrochemically can be performed by immersing a fixed dose $(1 \mathrm{~g} / \mathrm{L})$ of the saturated hydrogel in $1 \mathrm{M} \mathrm{HCl}$ as a regenerating solution. The 
regeneration performance of the adsorptive PAN-based HG was examined with and without electric current enhancement. The heavy metal desorption D (\%) has been calculated using the following equation (5): [37]

$$
\text { Desorption (D) } \%=\frac{\left(C_{d} * V_{d}\right)}{\left(C_{0}-C_{e}\right) V} 100
$$

Where: $\left(\mathrm{C}_{\mathrm{d}}\right)$ is the concentration of the solutes in a desorption solution $(\mathrm{mg} / \mathrm{L}),\left(\mathrm{V}_{\mathrm{d}}\right)$ is the volume of the desorption solution (in L) and (V) is the volume of the solution (in L).

\section{I- Chemical regeneration}

For adsorption/desorption cycle, the chemical regeneration was performed following the adsorption experiment, followed by solid-liquid separation by filtration, and washing.

- Adsorption step, was performed for the tested heavy metals $\left(\mathrm{Cr}^{3+}\right.$ and $\left.\mathrm{Ni}^{2+}\right)$, at the optimum conditions terms of $\mathrm{pH}$ (5.5, and 7 , respectively), salt initial concentration (10, and $20 \mathrm{ppm}$, as $\mathrm{C}_{0}$ respectively), obtained from the previously reported work [34]. The salt concentration in the solution after the adsorption $\left(\mathrm{C}_{\mathrm{e}}\right)$ was determined using FAA spectrometry.

- Washing step, at that step, the filtrated heavy metal loaded PAN-based HG was added to $100 \mathrm{ml}(10 \%)$ ethanol in a flask and shaken at (200 rpm) for (1 h) followed by filtration, and vacuum drying.

- Regeneration step, the heavy metal loaded PAN-based HG at its dried form was added to $(1 \mathrm{M}) \mathrm{HCl}$ and shaken at $(200 \mathrm{rpm})$ for $(3 \mathrm{~h})$ at ambient temperature. The salt concentration in the solution after the chemical desorption $\left(\mathrm{C}_{\mathrm{d}}\right)$ can then be determined after filtration.

- Washing step, the filtrated regenerated PAN-based HG was washed using $100 \mathrm{ml}$ distilled water.

The recyclable and recoverable ability of the PAN-based HG towards the tested heavy

metals $\left(\mathrm{Cr}^{3+}\right.$ and $\left.\mathrm{Ni}^{2+}\right)$, was determined through analyzing the salt concentration at the steps of the adsorption/chemical desorption cycle using FAA spectrometry followed by desorption (D \%) calculation using equation (5). 


\section{II- Electrically-assisted chemical regeneration}

- The electrically-assisted chemical regeneration experimental system setup, consists of a DC power supply (MCH-305D, Pakistan), and an electrochemical cell, as shown in (Fig. 1). Two cylindrical graphite electrodes (with $15 \mathrm{~cm}$ height, $2 \mathrm{~cm}$ outer diameter, and $1 \mathrm{~cm}$ inner diameter), were used as anodic electrode and cathodic electrode, plastic porous tube (filled with the specific weight of the PAN-based HG sample with $12 \mathrm{~cm}$ height, $1.8 \mathrm{~cm}$ outer diameter, $1.6 \mathrm{~cm}$ inner diameter), three holes' holder (for saving the fixed distance between the two electrodes and the in-between sample tube, which equal to $0.7 \mathrm{~cm}$ ), in a cell of $2 \mathrm{~L}$ total volume beaker container filled with $(1 \mathrm{M}) \mathrm{HCl}$ as an electrolyte which will also act as the regenerating solution.

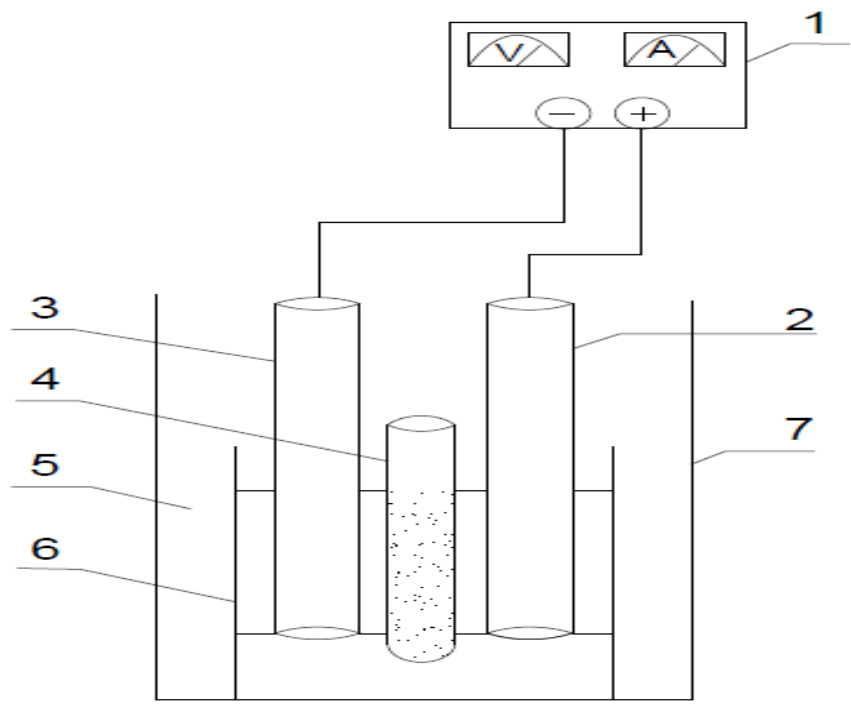

Figure 1: The electrically-assisted chemical regeneration system setup (i.e.; 1: DC power supply, 2: anodic electrode, 3: cathodic electrode, 4: plastic porous tube, 5: electrolyte, 6: three holes' holder, and 7: cell body).

- An electric current enhancement was attained by applying an electrical potential between the anodic and the cathodic electrodes controlled by a DC power supply, at which cell current and potential were measured. Using (1M) hydrochloric acid as an eluent, the immersed areas of anodic electrode and cathodic electrode were $25.12 \mathrm{~cm}^{2}$, with $(1 \mathrm{~g} / \mathrm{L})$ dose and was gently shaken $(100 \mathrm{rpm})$ at ambient temperature. 
The current intensity was fixed at 0.05 A through an average applied voltage of 2.4 and 3.5 volt for chromium and nickel desorption experiments, respectively. Through $4 \mathrm{~h} \mathrm{contact}$ time, each (30 min), a sample for analysis was taken, in which the salt concentration in the solution after the electrical-assisted chemical desorption $\left(\mathrm{C}_{\mathrm{d}}\right)$ at its specific time, was determined using the FAA spectrometry.

\section{Results and Discussion}

\subsection{Hydrogel Characterization}

\section{Fourier Transform Infrared Spectroscopy (FTIR)}

Infrared spectroscopy of PAN-based hydrogel is seen in comparison with pure PAN (Fig. 2). The PAN-based main hydrogel peaks 3400, 1700, and $1100 \mathrm{~cm}^{-1}$, are almost at the same position as the pure PAN main peaks $3400,3000,1100 \mathrm{~cm}^{-1}$ in the range of its main functional group allocated to $\left(\mathrm{CH}_{2}\right)$ the methylene group, $(\mathrm{CN})$ the cyanide group, and $(\mathrm{CO})$ the carbonyl group. The PAN-based hydrogel mean peaks occur at the same locations but at high intensity values.

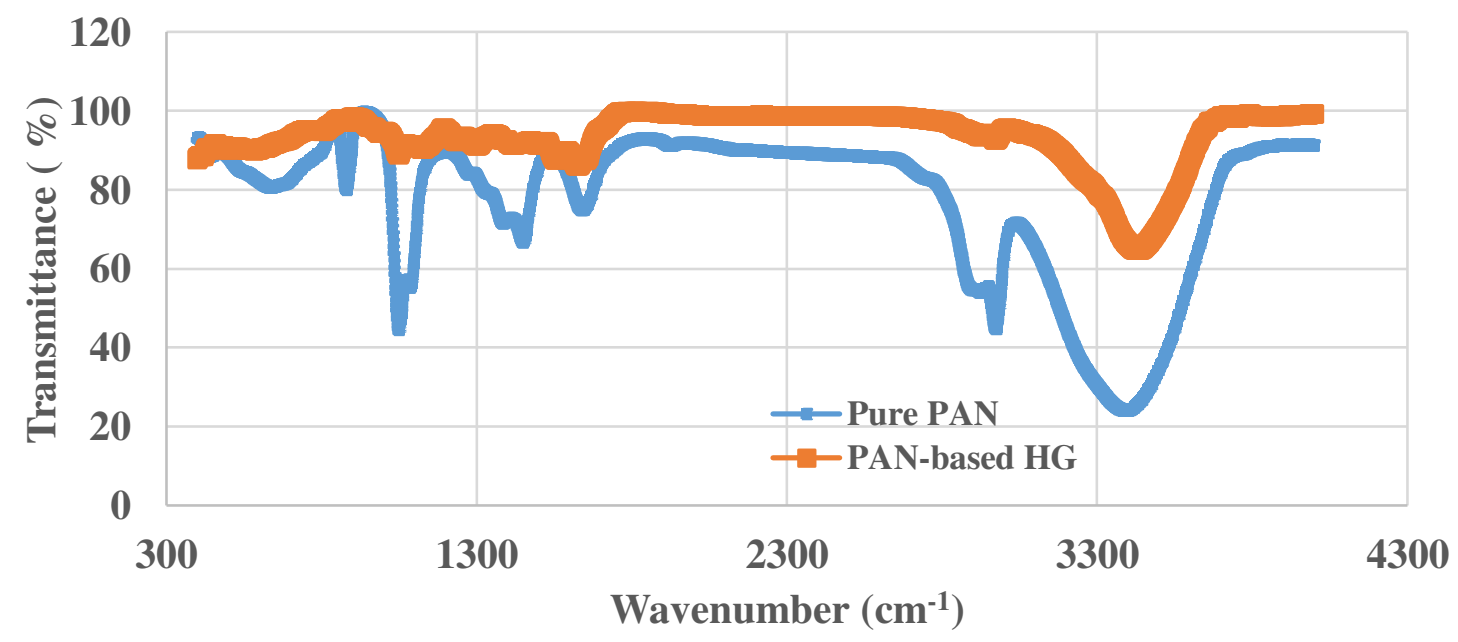

Figure 2: Infrared Spectrum (FTIR) of pure PAN, and the PAN-based HG .

\section{I- $\quad$ X-ray diffraction (XRD)}

X-Ray Diffraction patterns, corresponding to the PAN-based hydrogel in comparison with the pure PAN are illustrated in (Fig. 3), show a characteristic maximum peak at five different values at $\left(7.57^{\circ}, 8.221^{\circ}, 19.68^{\circ}, 24.78^{\circ}\right.$, and $\left.44.503^{\circ}\right)$ of $2 \theta$ values with d-spacing 
values at $(11.66,10.747,4.507,3.589$, and $2.03 \AA$ ), respectively. The XRD patterns of pure PAN have peak values at $(16.683,28.5$, and 72.357$)$ of $2 \theta$ values with d-spacing values at $(5.31,3.13$, and $1.31 \AA$ ), respectively.

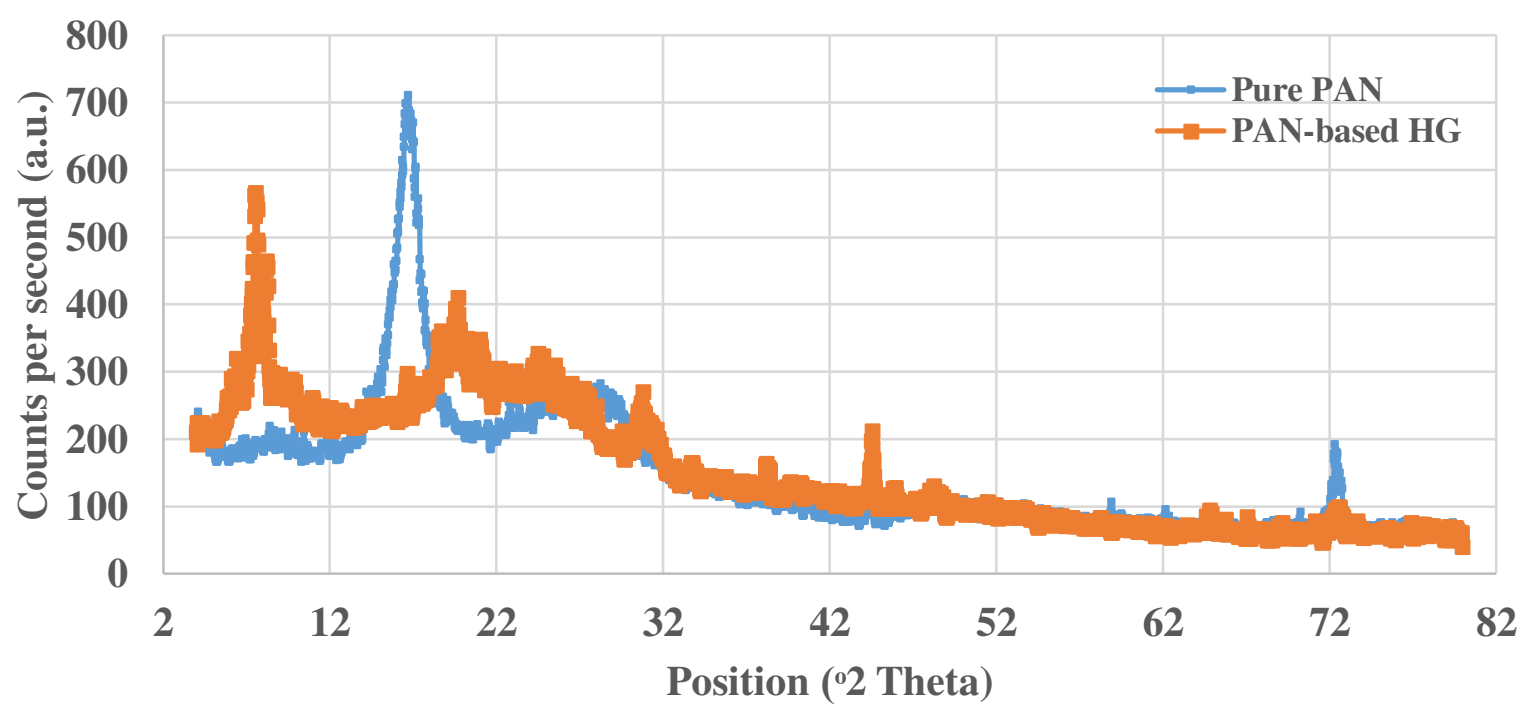

Figure 3: X-Ray diffraction for pure PAN, and the PAN-based HG.

\section{II- Scanning Electron Microscopy (SEM)}

The SEM monographs for the PAN-based hydrogel in comparison with the pure PAN are given in (Fig. 4), the pure PAN has uniform particles size between $(180-300 \mathrm{~nm})$ [38]. Whereas PAN-based hydrogel surface morphology suggested the absence of uniform particles and more pores instead. EDX data illustrated the difference in the amount of elements from pure to blended form in a randomly selected surface area within the scanning phase. The results indicated an increase in \% oxygen from (5.75 to $27.19 \%$ ) and a decrease in both \% carbon and nitrogen from (71.68 to $62.54 \%$ ), and (22.57 to $15.02 \%)$, respectively 


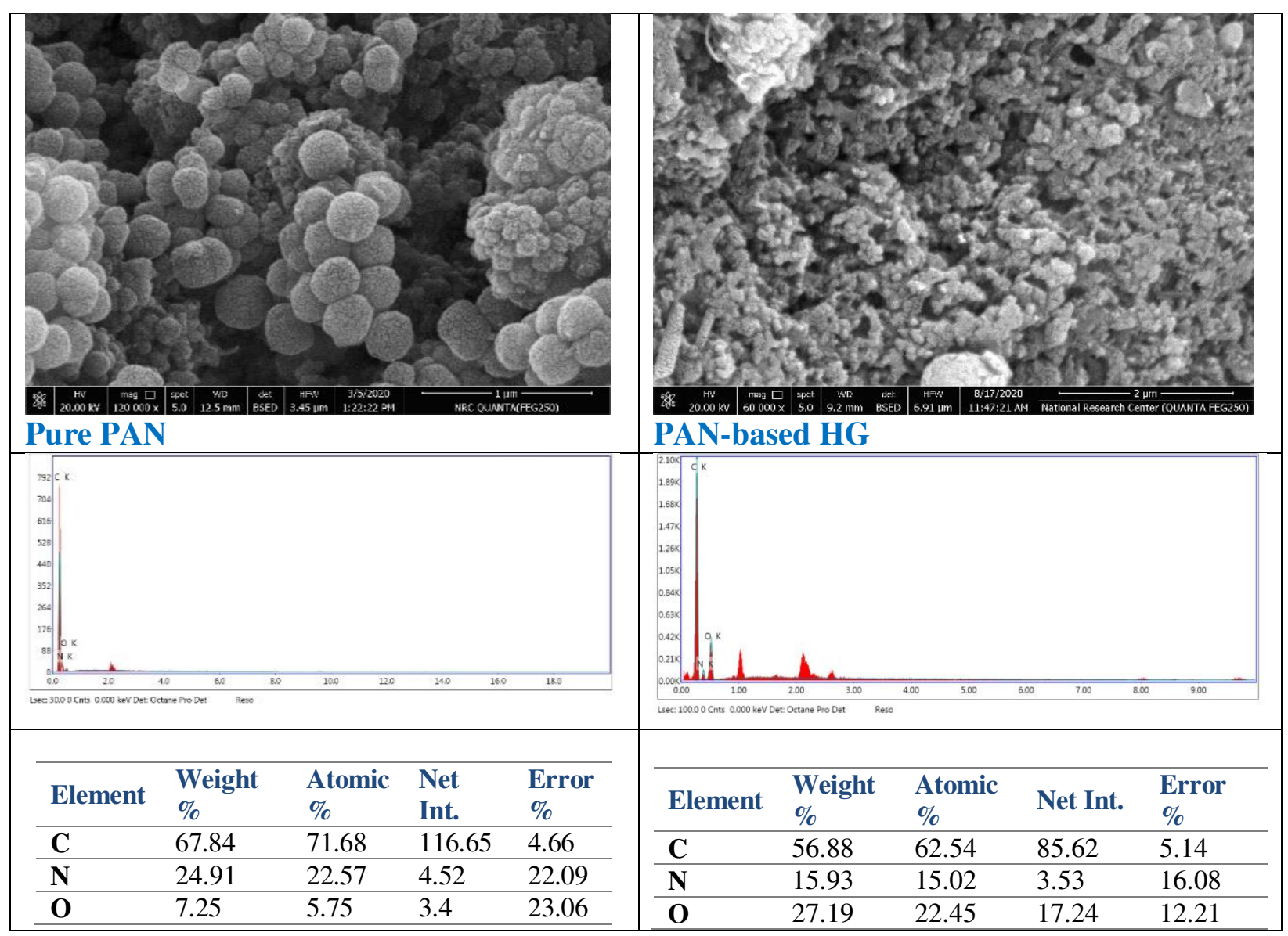

Figure 4: Scanning Electron Microscope (SEM) and their EDX data for pure PAN, and the PAN-based HG with $1 \mu \mathrm{m}$, and $2 \mu \mathrm{m}$, respectively

\section{III- Porosity measurements}

DFT mathematical modeling for the PAN-based hydrogel compared to the pure PAN resulted in an average pore size distribution as illustrated in (Fig. 5). Calculated surface area and total pore volume using Brunauer-Emmett-Teller (BET) analysis [39] shows an increase in the average pore size parameter from (3.295 to $4.3903 \mathrm{~nm}$ ), and a decrease in the other two parameters surface area, and total pore volume from $\left(26.223\right.$ to $12.85 \mathrm{~m}^{2} / \mathrm{g}$, and 0.038 to 0.019 $\mathrm{cm}^{3} / \mathrm{g}$ ), respectively between the pure PAN, and the PAN-based hydrogel, respectively. 


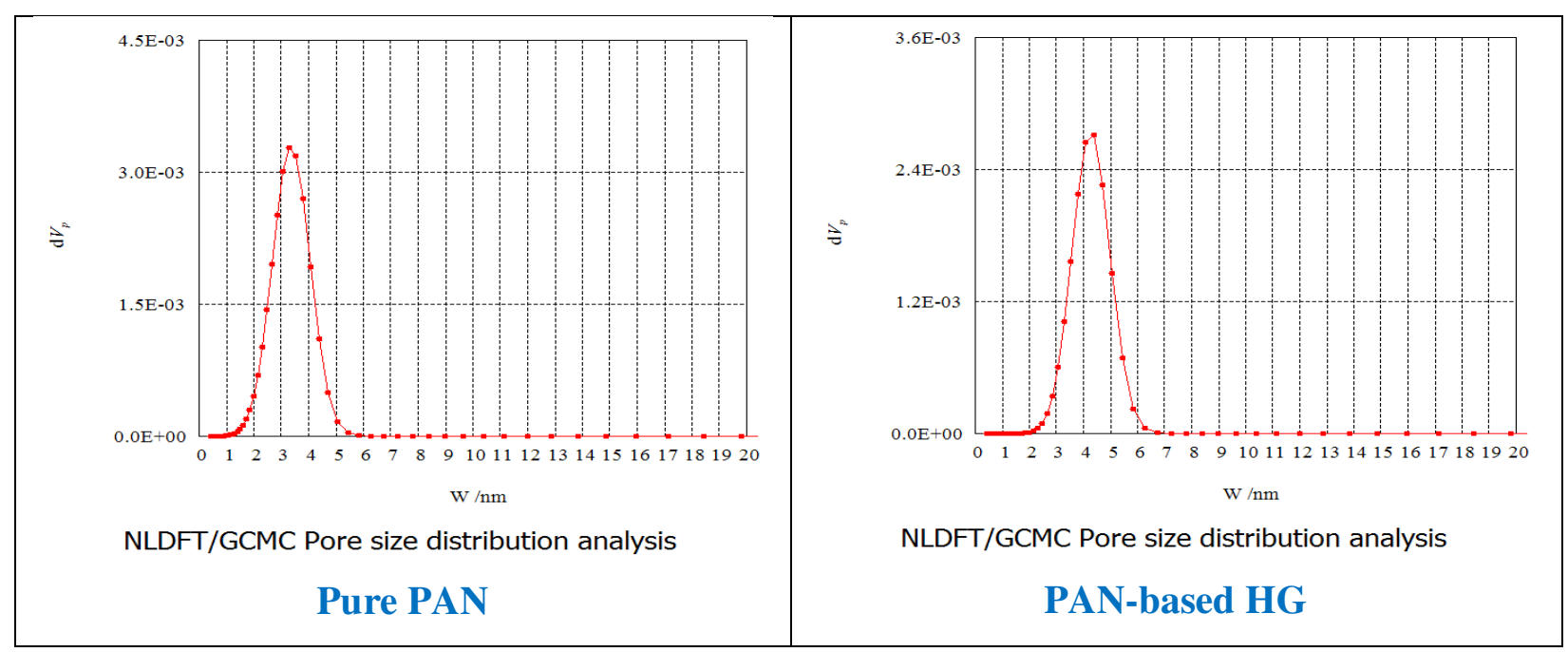

Figure 5: Pore size distribution analysis for pure PAN, and the PAN-based HG.

\section{IV- Electrical conductivity measurements}

Measurements of electrical conductivity were used to evaluate current changes at a fixed 1volt potential for PAN-based hydrogel. The results show an enhancement in the conductivity from $\left(<10^{-10}\right.$ to about $\left.10^{-5} \mathrm{~S} / \mathrm{cm}\right)$ between the pure PAN, and the PAN-based hydrogel as illustrated in (Fig. 6).

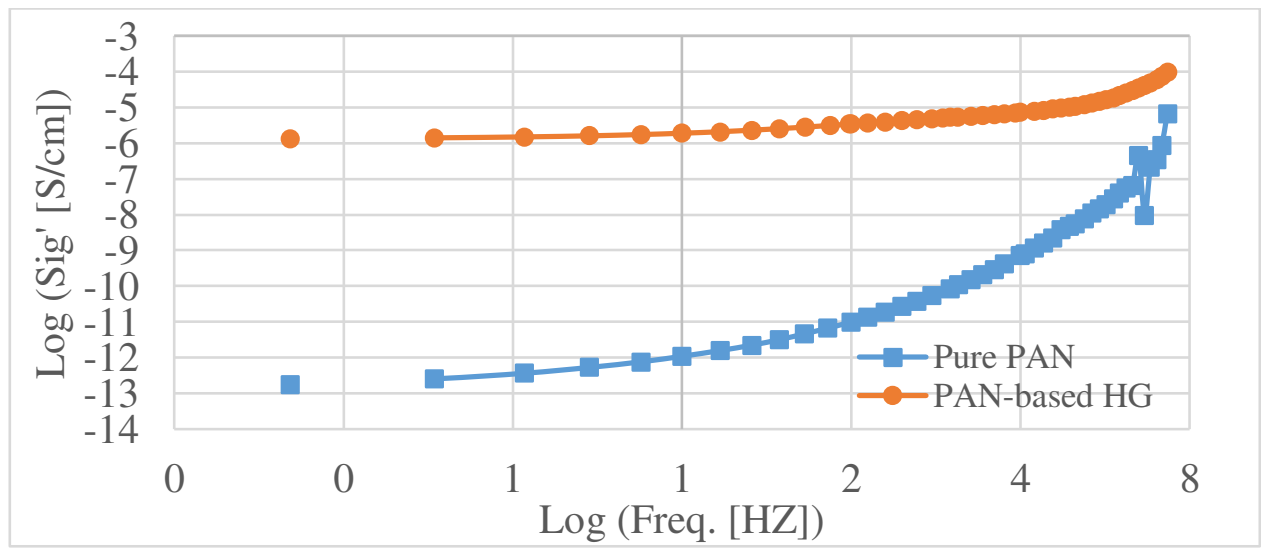

Figure 6: The conductivity for pure PAN, and the PAN-based HG . 


\section{V- Swelling water ratio (SWR) measurements}

The swelling of the PAN-based HG tested through calculation of the swelling water ratio (SWR) was found to be (497\%) which is considered to some extent higher than the reported value for pure PVA hydrogel of $416 \%$ [40].

\subsection{Adsorption}

\subsubsection{Adsorption experimental results}

The maximum outcome of chromium and nickel adsorption as examined in the authors previous work [34] was found to be for chromium (10 mg/L) initial salt concentration, (5.5) $\mathrm{pH}$, and $(1 \mathrm{~h})$ contact time. Whereas the optimum adsorption conditions for nickel were $(20 \mathrm{mg} / \mathrm{L})$ initial salt concentration, (7) $\mathrm{pH}$, and (2 h) contact time.

PAN-based HG adsorption performance towards chromium was found to be (95\%) removal efficiency $\mathrm{R}(\%)$ and $(8.082 \mathrm{mg} / \mathrm{g})$ adsorption capacities $\mathrm{q}(\mathrm{mg} / \mathrm{g})$. while for nickel (97.3 $\%)$ removal efficiency $\mathrm{R}(\%)$ and $(17.437 \mathrm{mg} / \mathrm{g})$ adsorption capacities $\mathrm{q}(\mathrm{mg} / \mathrm{g})$ were reported.

\subsubsection{Adsorption isotherms}

Chromium and nickel adsorption isotherm onto PAN-based HG was tested with various initial salt concentrations: $2.5,5,7.5,10,12.5,15,17.5$, and $20 \mathrm{mg} / \mathrm{L}$, with fixed additional adsorption parameters including dose $(1 \mathrm{~g} / \mathrm{L})$ polymeric hydrogel blend to salt solution volume with optimum $\mathrm{pH}(5.5,7)$ and $(1,2 \mathrm{~h})$ of optimal contact time for $\mathrm{Cr}^{3+}$ and $\mathrm{Ni}^{2+}$, respectively were investigated.

The value of $\mathrm{Q}_{0}(\mathrm{mg} / \mathrm{g})$ and $\mathrm{b}\left(\mathrm{dm}^{3} / \mathrm{mg}\right)$ can be calculated from the slope and the intercept of the linear plot of $\left(\mathrm{C}_{\mathrm{e}} / \mathrm{q}_{\mathrm{e}}\right)$ versus $\left(\mathrm{C}_{\mathrm{e}}\right)$, respectively for Langmuir model as shown in $(\mathbf{F i g} . \mathbf{7 , 8})$ with its nonlinear, and linear forms expressed by equations (7), and (8) as follow:

$$
\begin{gathered}
q_{e}=\frac{Q_{e} b C_{e}}{1+b C_{e}} \\
\frac{C_{e}}{q_{e}}=\frac{1}{b Q_{e}}+\frac{C_{e}}{Q_{0}}
\end{gathered}
$$


Where, $\mathrm{q}_{\mathrm{e}}$ the equilibrium metal ions concentration in solution after sorption, $\mathrm{C}_{\mathrm{e}}$ concentration of liquid at the solid phase, $b$ is the adsorption equilibrium constant $\left(\mathrm{dm}^{3} / \mathrm{mg}\right)$ related to the apparent adsorption energy and $\mathrm{Q}_{0}$ is maximum single-layer coverage potential $(\mathrm{mg} / \mathrm{g})$.

On the other hand, the value of $\mathrm{K}_{\mathrm{f}}$, and $\mathrm{n}$ can be respectively calculated from slope, and intercepted linear plot of $\left(\log \mathrm{q}_{\mathrm{e}}\right)$ versus $\left(\log \mathrm{C}_{\mathrm{e}}\right)$ for Freundlich model as given in (Fig. 9, 10) with its nonlinear, and linear forms as expressed by equations (9), and (10), respectively.

$$
\begin{gathered}
q_{e}=K_{f} C_{e^{\frac{1}{n}}} \\
\log q_{e}=\log K_{f}+\frac{1}{n} \log C_{e}
\end{gathered}
$$

Where, $\mathrm{K}_{\mathrm{f}}$ is Freundlich constant, this provides the absolute adsorption capability of the adsorbent correlated with the bonding energy, and $\mathrm{n}$ is the heterogeneity factor or Freundlich

\begin{tabular}{|c|c|c|}
\hline Parameter & Chromium & Nickel \\
\hline \multicolumn{3}{|c|}{ Langmuir model } \\
\hline $\mathbf{Q}_{0}$ & -2.391 & -109.409 \\
\hline b & -0.229 & -0.025 \\
\hline $\mathbf{R}^{2}$ & 0.4886 & 0.5718 \\
\hline \multicolumn{3}{|c|}{ Freundlich model } \\
\hline$\overline{\mathbf{K}_{\mathrm{f}}}$ & 0.853 & 3.398 \\
\hline $\mathbf{n}$ & 0.271 & 0.595 \\
\hline $\mathbf{R}^{2}$ & 0.763 & 0.914 \\
\hline
\end{tabular}
coefficient.

Investigational findings are found to be more fitted to Freundlich rather than Langmuir model, which indicates that unlimited and unsaturated solute adsorption sites on the adsorbent surface reflecting the non-ideal sorption involving heterogeneous physisorption. 


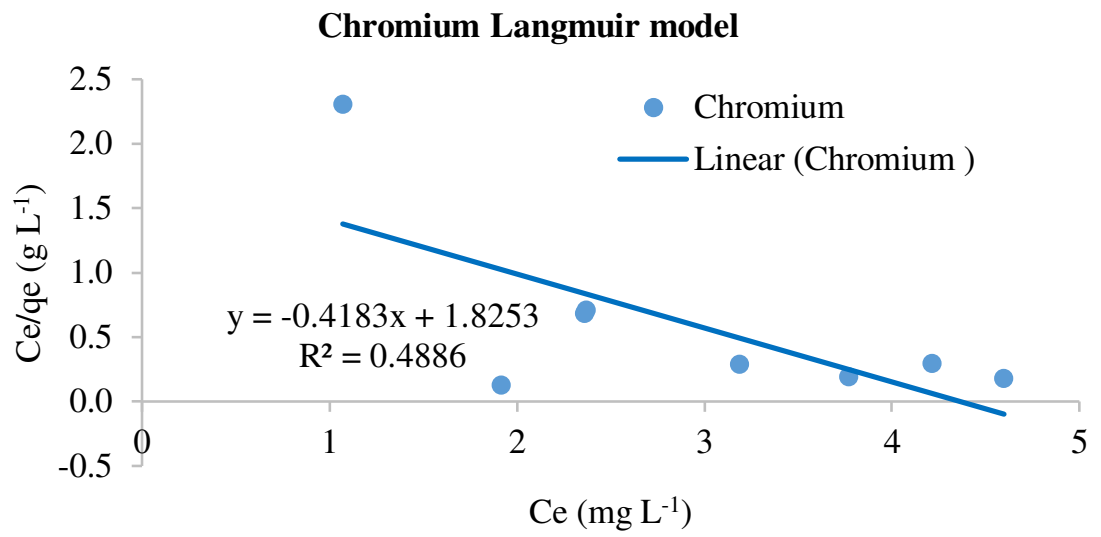

Figure 7: Langmuir adsorption isotherm for chromium (i.e., qe: amount of adsorbate in the adsorbent at equilibrium (mg/g), and Ce: equilibrium concentration (mg/L)).

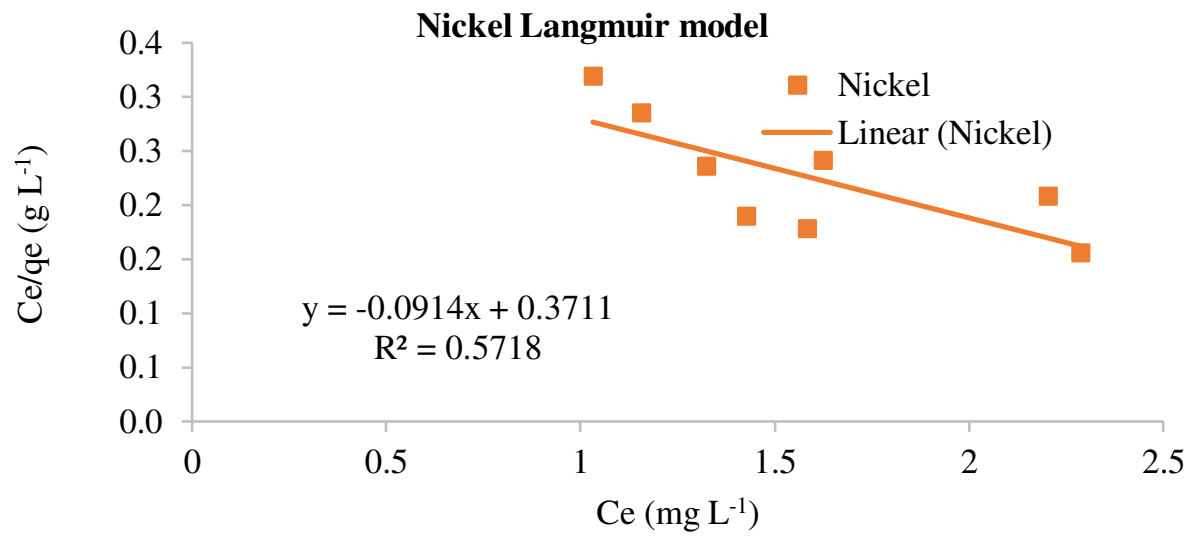

Figure 8: Langmuir adsorption isotherm for nickel (i.e., qe: amount of adsorbate in the adsorbent at equilibrium (mg/g), and Ce: equilibrium concentration $(\mathrm{mg} / \mathrm{L}))$. 


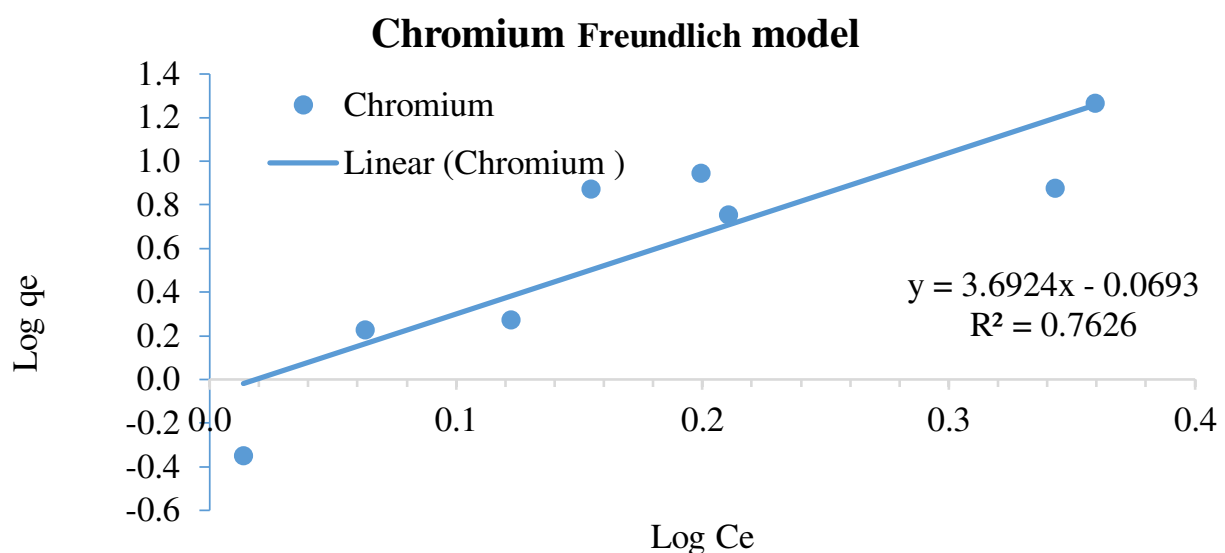

Figure 9: Freundlich adsorption isotherm for chromium (i.e., qe: amount of adsorbate in the adsorbent at equilibrium (mg/g), and Ce: equilibrium concentration (mg/L)).

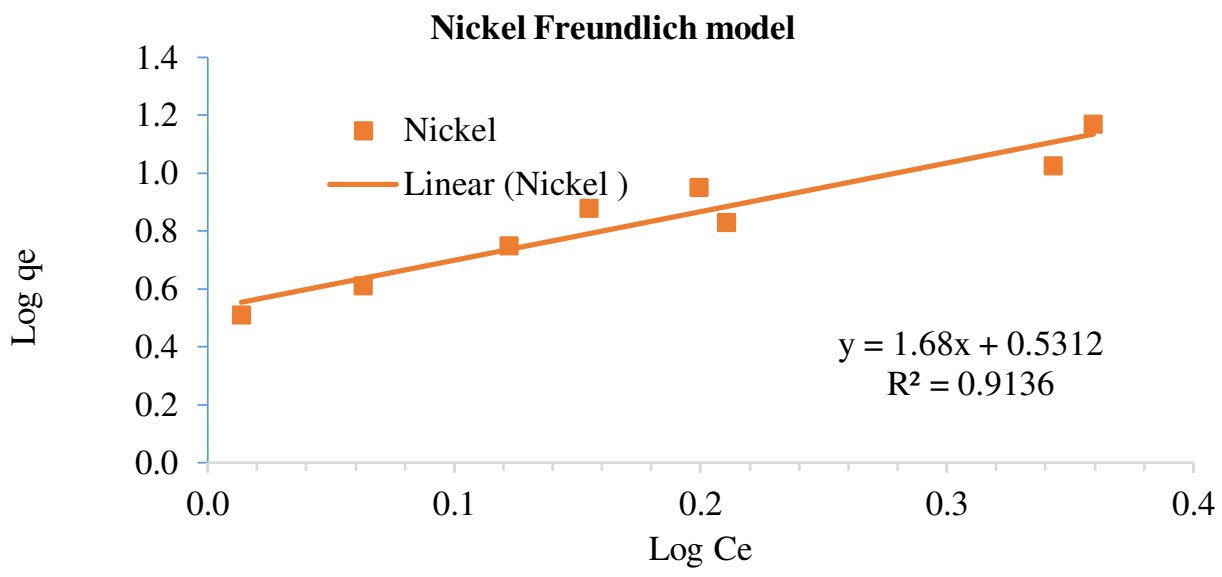

Figure 10: Freundlich adsorption isotherm for nickel (i.e., qe: amount of adsorbate in the adsorbent at equilibrium (mg/g), and Ce: equilibrium concentration (mg/L)). 


\subsubsection{Adsorption kinetics}

Chromium and nickel adsorption kinetics onto PAN-based HG was tested with various contact time: 15, 30, 45, 60, 75, 90, 105, and $120 \mathrm{~min}$, at fixed additional adsorption parameters including dose $(1 \mathrm{~g} / \mathrm{L})$ polymeric hydrogel blend to salt solution volume with optimum $\mathrm{pH}(5.5$, 7) and $(10,20 \mathrm{mg} / \mathrm{L})$ optimum initial salt concentration for $\mathrm{Cr}^{3+}$ and $\mathrm{Ni}^{2+}$, respectively were investigated.

The value of $K_{a d}\left(\min ^{-1}\right)$ can be calculated from the slope of the linear plot of $\ln \left(\mathrm{q}_{\mathrm{e}}-\mathrm{q}_{\mathrm{t}}\right)$ versus $t$ (min) for Pseudo-first-order in shown in (Fig. 11, 12) with its nonlinear, and linear forms expressed by equations (11), and (12), respectively.

$$
\begin{gathered}
\frac{d q_{t}}{d t}=K_{a d}\left(q_{e}-q_{t}\right) \\
\log \left(q_{e}-q_{t}\right)=\log q_{e}-K_{a d} \frac{t}{2.303}
\end{gathered}
$$

Where, $\mathrm{q}_{\mathrm{e}}$ and $\mathrm{q}_{\mathrm{t}}$ represent the quantity of metal ion sequestered $(\mathrm{mg} / \mathrm{g})$ at equilibrium time and at any instant of time $\mathrm{t}$, respectively, and $\mathrm{k}_{\mathrm{ad}}\left(\mathrm{min}^{-1}\right)$ is the rate constant of the pseudo first order adsorption.

On the other hand, the value of $\mathrm{K}_{2}\left(\mathrm{~g} \mathrm{mg}^{-1} \mathrm{~min}^{-1}\right)$ can be calculated by intercepting the linear plot of $t / q_{t}$ versus $t(\mathrm{~min})$ for Pseudo-second-order as in (Fig. 13, 14). with its nonlinear, and linear forms expressed by equations (13), and (14), respectively.

$$
\begin{gathered}
\frac{d q_{t}}{d t}=K_{2}\left(q_{\mathrm{e}}-q_{\mathrm{t}}\right)^{2} \\
\frac{t}{q_{t}}=\frac{1}{K_{2} q_{\mathrm{e}}^{2}}+\left(\frac{1}{q_{\mathrm{e}}}\right) t
\end{gathered}
$$

where, $\mathrm{k}_{2}\left(\mathrm{~g} \mathrm{mg}^{-1} \mathrm{~min}^{-1}\right)$ is the second order rate constant 
Table 2: The sorption parameters and correlation factors derived

from Pseudo- first and second order models.

\begin{tabular}{ccc}
\hline \multicolumn{1}{l}{ Parameter } & Chromium & Nickel \\
\hline \multicolumn{2}{l}{ Pseudo-first-order (PFO) model } & \\
\hline $\mathbf{K}_{\mathbf{a d}}$ & -0.009 & -0.014 \\
$\mathbf{R}^{\mathbf{2}}$ & 0.7467 & 0.7176 \\
\hline Pseudo-second-order (PSO) model & \\
\hline $\mathbf{K}_{\mathbf{2}}$ & 0.021 & 0.005 \\
$\mathbf{R}^{2}$ & 0.992 & 1.000 \\
\hline
\end{tabular}

Investigational findings are found to be more fitted to Pseudo-second-order (PSO) rather than Pseudo-first-order (PFO) model, which indicates that the rate of adsorption of solute is proportional to the available sites on the adsorbent and thus, reaction rate depends on the amount of solute on the surface of the adsorbent.

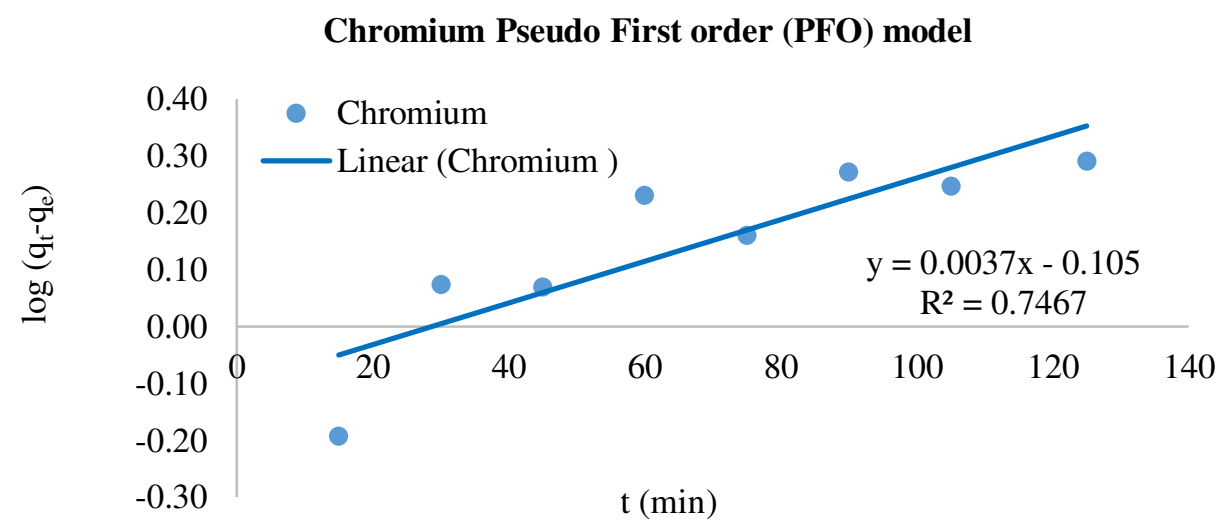

Figure 11: Pseudo first order (PSO) kinetic modeling for chromium. 


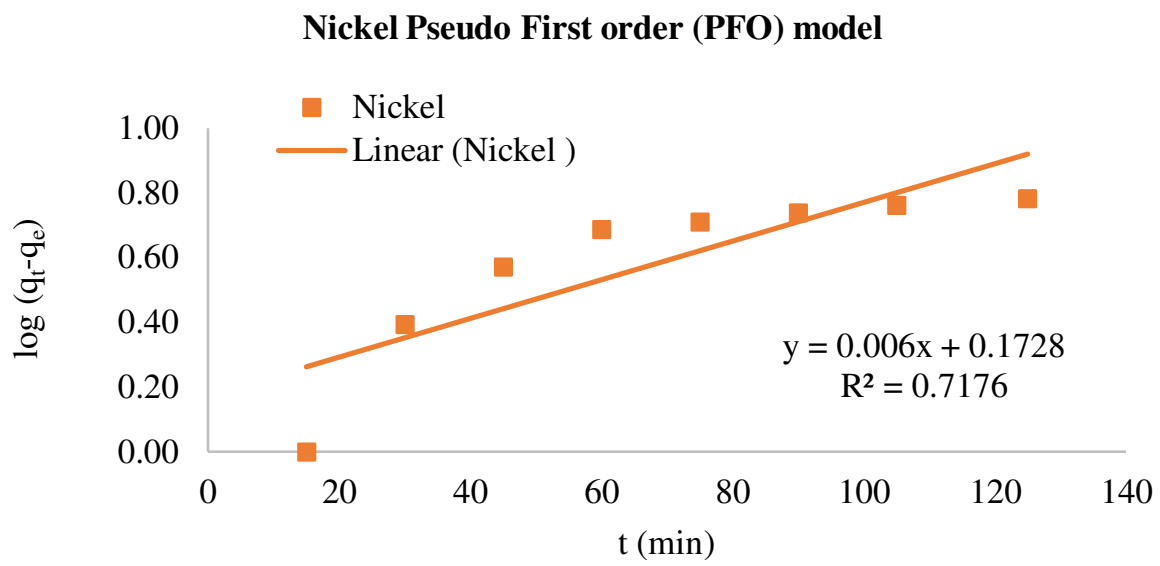

Figure 12: Pseudo first order (PSO) kinetic modeling for nickel.

\section{Chromium Pseudo second order (PSO) model}

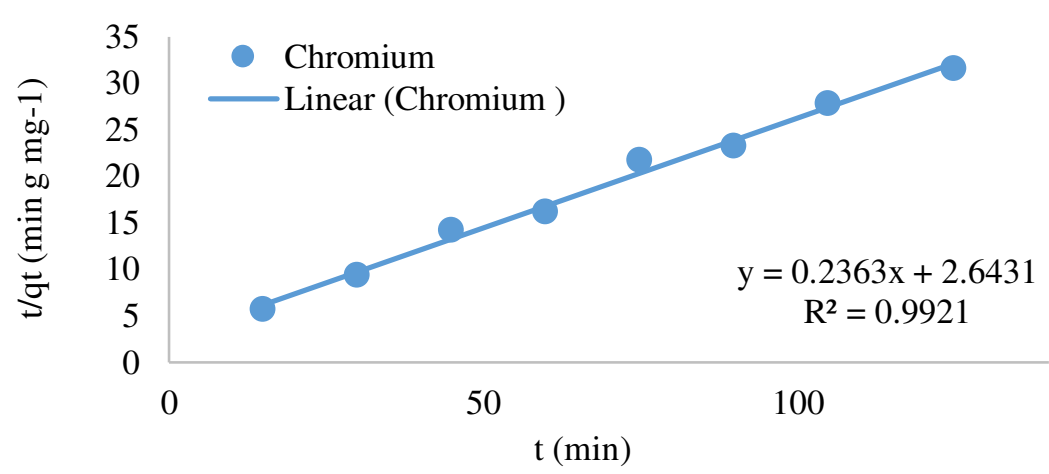

Figure 13: Pseudo second order (PSO) kinetic modeling for chromium.

\section{Nickel Pseudo second order (PSO) model}

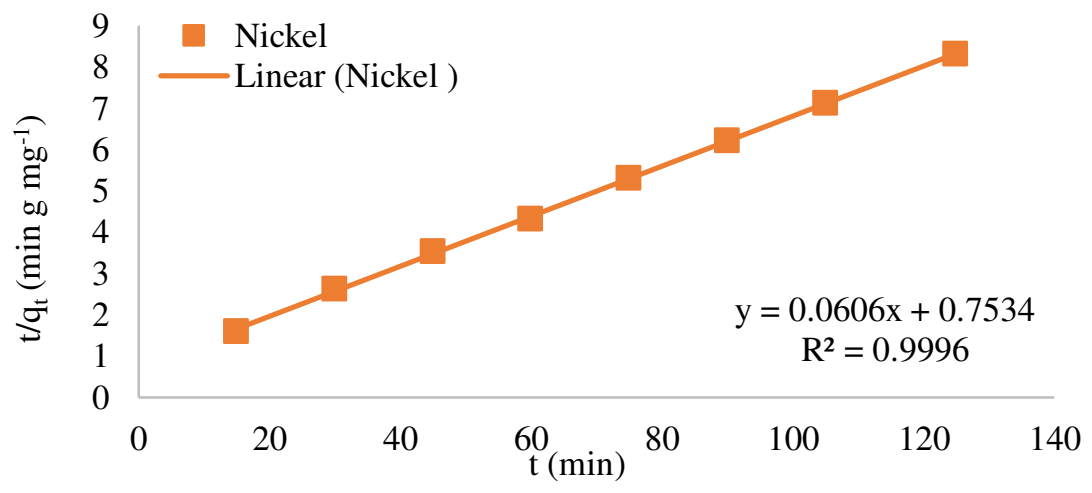

Figure 14: Pseudo second order (PSO) kinetic modeling for nickel. 


\subsection{Chemical Regeneration}

The adsorption/chemical desorption cycle without electrical current enhancement, was performed in steps starting with adsorption, washing, chemical regeneration, ending with another washing step for complete cycle, specifically mentioned in the methodology. Applying the optimum condition terms as $\mathrm{pH}$, salt initial concentration $\left(\mathrm{C}_{0}\right)$, and contact time for the tested heavy metals $\mathrm{Cr}^{3+}$ and $\mathrm{Ni}^{2+}$ as given before.

For chromium adsorption/chemical desorption cycle, the resulted adsorption potential q (mg/g), removal percentage R (\%), and chemical percentage desorption D (\%) which were found to be $(8.082,95$, and 15.58$)$, respectively.

While for Nickel adsorption/chemical desorption cycle, the resulted adsorption potential q (mg/g), removal percentage R (\%), and chemically percentage desorption D (\%) which were found to be (17.437, 97.3, and 27.27), respectively.

\subsection{Electrically-assisted chemical regeneration}

Adsorption/electrically-assisted chemical desorption cycle with electric current enhancement, for tested heavy metals $\mathrm{Cr}^{3+}$ and $\mathrm{Ni}^{2+}$ as mentioned in adsorption/chemical desorption cycle.

For chromium adsorption/electrically assisted chemical desorption cycle, the resulted adsorption potential q (mg/g), removal percentage (R\%), and electrically-assisted maximum percentage desorption D (\%) were found to be (6.0, 67.3, and 51.6), respectively.

Whereas for nickel adsorption/electrically-assisted chemical desorption cycle, the resulted adsorption potential $\mathrm{q}(\mathrm{mg} / \mathrm{g})$, removal percentage $(\mathrm{R} \%)$, and electrically-assisted maximum percentage desorption (D\%) were found to be $(17.9,91.7$, and 98.3$)$, respectively.

The electrically-assisted percentage desorption (D\%) with time, was determined as shown in (Fig. 15). The results indicate that the maximum desorption value was found after (1, and $3 \mathrm{~h}$ ) for chromium, and nickel, respectively and shows higher desorption ability towards nickel compared to chromium. 


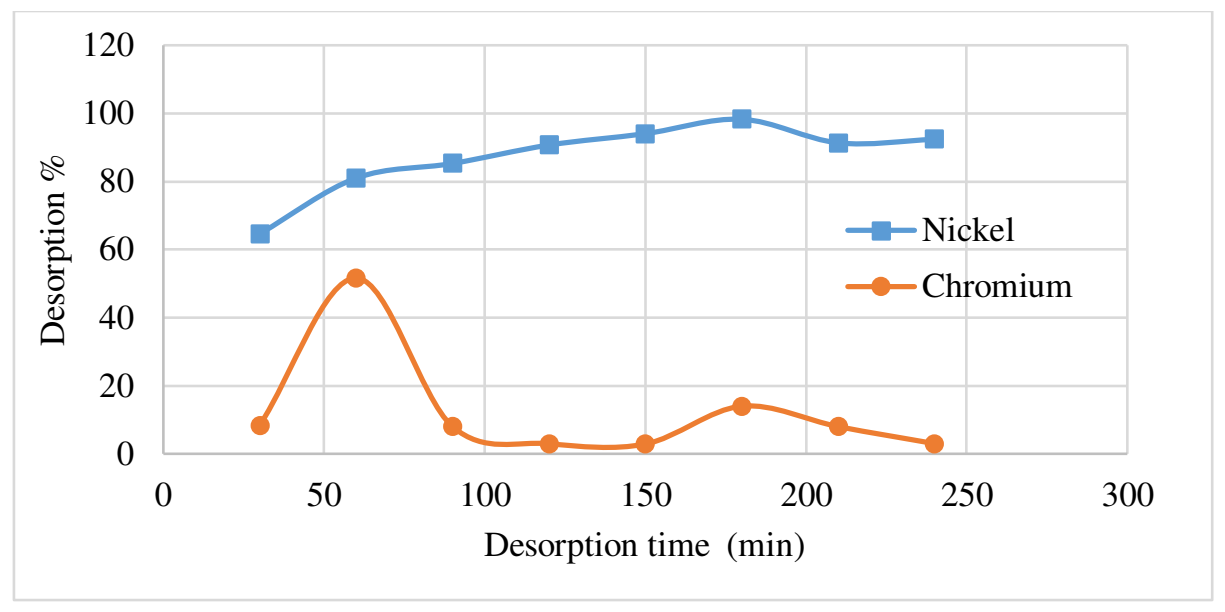

Figure 15: The desorption percentage values with time for chromium and nickel.

The chemical and electrically-assisted chemical desorption results indicate that good enhancement was noticed due to the electric current in the desorption performance of the heavy metal loaded PAN-based HG as shown in (Fig. 16) showing the inconsistency between them towards the tested heavy metal salts (chromium, and nickel).

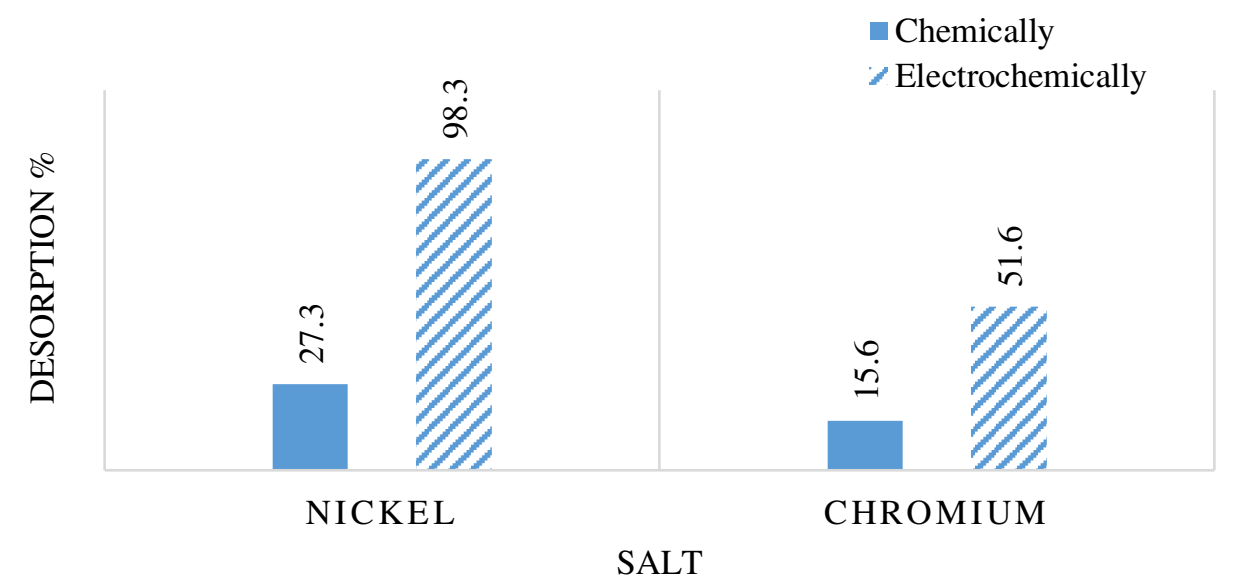

Figure 16: The desorption percentage values for chromium and nickel chemically and electrochemically. 


\section{Conclusion}

The PAN-based HG adsorption performance towards the chromium was found to be (95 $\%$ ) removal efficiency $\mathrm{R}(\%)$ and $(8.082 \mathrm{mg} / \mathrm{g})$ adsorption capacities $\mathrm{q}(\mathrm{mg} / \mathrm{g})$. On the other hand, $(97.3 \%)$ removal efficiency $\mathrm{R}(\%)$ and $(17.437 \mathrm{mg} / \mathrm{g})$ adsorption capacities $\mathrm{q}(\mathrm{mg} / \mathrm{g})$ in case of Nickel. The adsorption isotherm and kinetic models were used to evaluate the metal uptake data. The isotherm data was fitted to Freundlich while kinetic data fitted with the pseudosecond-order (PSO) model, respectively. The PAN-based HG blend which was loaded with the investigated heavy metals were regenerated chemically and electrochemically. The chromium salt was desorbed by $15.6 \%$ chemically and $51.6 \%$ electrochemically after $1 \mathrm{~h}$. The nickel salt was desorbed by $27.3 \%$ chemically and $98.3 \%$ electrochemically after $3 \mathrm{~h}$. This indicates good desorption enhancement in the desorption performance for using the electric current. 


\section{References}

[1] M. A. Hussain, G. Muhammad, M. T. Haseeb, and M. N. Tahir, Quince Seed Mucilage: A Stimuli-Responsive/Smart Biopolymer. 2019.

[2] M. Bahram, N. Mohseni, and M. Moghtader, "An Introduction to Hydrogels and Some Recent Applications,” Emerg. Concepts Anal. Appl. Hydrogels, 2016, doi: 10.5772/64301.

[3] Lh. Yahia, "History and Applications of Hydrogels," J. Biomed. Sci., vol. 04, no. 02, 2015, doi: 10.4172/2254-609x.100013.

[4] L. Pan et al., "Hierarchical nanostructured conducting polymer hydrogel with high electrochemical activity," Proc. Natl. Acad. Sci. U. S. A., vol. 109, no. 24, pp. 9287-9292, 2012, doi: 10.1073/pnas.1202636109.

[5] P. Chansai, A. Sirivat, S. Niamlang, D. Chotpattananont, and K. Viravaidya-Pasuwat, "Controlled transdermal iontophoresis of sulfosalicylic acid from polypyrrole/poly(acrylic acid) hydrogel," Int. J. Pharm., vol. 381, no. 1, pp. 25-33, 2009, doi: 10.1016/j.ijpharm.2009.07.019.

[6] Y. Li, K. G. Neoh, and E. T. Kang, "Controlled release of heparin from polypyrrolepoly(vinyl alcohol) assembly by electrical stimulation," J. Biomed. Mater. Res. - Part A, vol. 73, no. 2, pp. 171-181, 2005, doi: 10.1002/jbm.a.30286.

[7] D. Ge et al., "Coating metals on cellulose-polypyrrole composites: A new route to selfpowered drug delivery system," Electrochem. commun., vol. 12, no. 10, pp. 1367-1370, 2010, doi: 10.1016/j.elecom.2010.07.022.

[8] N. Paradee and A. Sirivat, "Electrically controlled release of benzoic acid from poly(3,4ethylenedioxythiophene)/alginate matrix: Effect of conductive poly(3,4ethylenedioxythiophene) morphology," J. Phys. Chem. B, vol. 118, no. 31, pp. 92639271, 2014, doi: 10.1021/jp502674f.

[9] M. Sasaki, B. C. Karikkineth, K. Nagamine, H. Kaji, K. Torimitsu, and M. Nishizawa, "Highly Conductive Stretchable and Biocompatible Electrode-Hydrogel Hybrids for Advanced Tissue Engineering," Adv. Healthc. Mater., vol. 3, no. 11, pp. 1919-1927, 2014, doi: 10.1002/adhm.201400209.

[10] Y. S. Kim et al., "Highly conductive and hydrated PEG-based hydrogels for the potential application of a tissue engineering scaffold," React. Funct. Polym., vol. 109, pp. 15-22, 2016, doi: 10.1016/j.reactfunctpolym.2016.09.003.

[11] H. Ding et al., "Biologically derived soft conducting hydrogels using heparin-doped polymer networks," ACS Nano, vol. 8, no. 5, pp. 4348-4357, 2014, doi: $10.1021 / \mathrm{nn} 406019 \mathrm{~m}$.

[12] V. Guarino, M. A. Alvarez-Perez, A. Borriello, T. Napolitano, and L. Ambrosio, "Conductive PANi/PEGDA Macroporous Hydrogels For Nerve Regeneration," Adv. Healthc. Mater., vol. 2, no. 1, pp. 218-227, 2013, doi: 10.1002/adhm.201200152.

[13] C. J. Pérez-Martínez et al., "Electroconductive nanocomposite hydrogel for pulsatile drug 
release," React. Funct. Polym., vol. 100, pp. 12-17, 2016, doi: 10.1016/j.reactfunctpolym.2015.12.017.

[14] T. S. Tsai et al., "A polyvinyl alcohol-polyaniline based electro-conductive hydrogel for controlled stimuli-actuable release of indomethacin," Polymers (Basel)., vol. 3, no. 1, pp. 150-172, 2011, doi: 10.3390/polym3010150.

[15] K. Singh, N. A. Renu, and M. Agarwal, "Methodologies for removal of heavy metal ions from wastewater: an overview," Interdiscip. Environ. Rev., vol. 18, no. 2, p. 124, 2017, doi: 10.1504/ier.2017.10008828.

[16] F. N. Muya, C. E. Sunday, P. Baker, and E. Iwuoha, "Environmental remediation of heavy metal ions from aqueous solution through hydrogel adsorption: A critical review," Water Sci. Technol., vol. 73, no. 5, pp. 983-992, 2016, doi: 10.2166/wst.2015.567.

[17] M. İnce and O. Kaplan İnce, "An Overview of Adsorption Technique for Heavy Metal Removal from Water/Wastewater: A Critical Review," Int. J. Pure Appl. Sci., vol. 3, no. 2, pp. 10-19, 2017, doi: 10.29132/ijpas.372335.

[18] J. Wang, "Reuse of Heavy Metal from Industrial Effluent Water," IOP Conf. Ser. Earth Environ. Sci., vol. 199, no. 4, 2018, doi: 10.1088/1755-1315/199/4/042002.

[19] K. C. Khulbe and T. Matsuura, "Removal of heavy metals and pollutants by membrane adsorption techniques," Appl. Water Sci., vol. 8, no. 1, pp. 1-30, 2018, doi: 10.1007/s13201-018-0661-6.

[20] R. Arora, "Adsorption of heavy metals-a review," Mater. Today Proc., vol. 18, pp. 47454750, 2019, doi: 10.1016/j.matpr.2019.07.462.

[21] Renu, M. Agarwal, and K. Singh, "Heavy metal removal from wastewater using various adsorbents: A review," J. Water Reuse Desalin., vol. 7, no. 4, pp. 387-419, 2017, doi: 10.2166/wrd.2016.104.

[22] M. Czikkely, E. Neubauer, I. Fekete, P. Ymeri, and C. Fogarassy, "Review of heavy metal adsorption processes by several organic matters from wastewaters," Water (Switzerland), vol. 10, no. 10, pp. 1-15, 2018, doi: 10.3390/w10101377.

[23] V. Bobade and N. Eshtiagi, "Heavy Metals Removal from Wastewater by Adsorption Process : A Review," APCChE 2015 Congr. Inc. Chemeca 2015, vol. 6, no. 6, pp. 312$317,2015$.

[24] S. Koutsonas, "Electrical conductivity of degraded polyacrylonitrile powder by microwave irradiation for supercapacitor devices or other mobile applications," Mater. Lett., vol. 193, pp. 203-205, 2017, doi: 10.1016/j.matlet.2017.02.001.

[25] A. Dimov, T. Godjevargova, and A. Simeonova, "Adsorption of heavy metal ions from aqueous solutions by porous polyacrylonitrile beads," J. Appl. Polym. Sci., vol. 83, no. 14, pp. 3036-3044, 2002, doi: 10.1002/app.2334.

[26] N. M. Barkoula, B. Alcock, N. O. Cabrera, and T. Peijs, "Flame-Retardancy Properties of Intumescent Ammonium Poly(Phosphate) and Mineral Filler Magnesium Hydroxide in Combination with Graphene," Polym. Polym. Compos., vol. 16, no. 2, pp. 101-113, 2008, 
doi: $10.1002 / p c$.

[27] A. H. Shalla, Z. Yaseen, M. A. Bhat, T. A. Rangreez, and M. Maswal, "Recent review for removal of metal ions by hydrogels," Sep. Sci. Technol., vol. 54, no. 1, pp. 89-100, 2019, doi: 10.1080/01496395.2018.1503307.

[28] S. Lata, P. K. Singh, and S. R. Samadder, "Regeneration of adsorbents and recovery of heavy metals: a review," Int. J. Environ. Sci. Technol., vol. 12, no. 4, pp. 1461-1478, 2015, doi: 10.1007/s13762-014-0714-9.

[29] J. Wang and C. Chen, "Biosorbents for heavy metals removal and their future," Biotechnol. Adv., vol. 27, no. 2, pp. 195-226, 2009, doi: 10.1016/j.biotechadv.2008.11.002.

[30] A. Chatterjee and J. Abraham, "Desorption of heavy metals from metal loaded sorbents and e-wastes: A review," Biotechnol. Lett., vol. 41, no. 3, pp. 319-333, 2019, doi: 10.1007/s10529-019-02650-0.

[31] M. Khan and I. M. C. Lo, "A holistic review of hydrogel applications in the adsorptive removal of aqueous pollutants: Recent progress, challenges, and perspectives," Water Res., vol. 106, pp. 259-271, 2016, doi: 10.1016/j.watres.2016.10.008.

[32] H. Kamata, Y. Akagi, Y. Kayasuga-Kariya, U. Il Chung, and T. Sakai, "Nonswellable' hydrogel without mechanical hysteresis," Science (80-. )., vol. 343, no. 6173, pp. 873875, 2014, doi: 10.1126/science.1247811.

[33] Z. Al-Qodah and M. Al-Shannag, "Heavy metal ions removal from wastewater using electrocoagulation processes: A comprehensive review," Sep. Sci. Technol., vol. 52, no. 17, pp. 2649-2676, 2017, doi: 10.1080/01496395.2017.1373677.

[34] A. A. El Mansoub, M. M. El Sayed, A. M. G. Abulnour, H. M. Fahmy, and R. M. El Nashar, "Characterization and Performance Analysis of an Adsorptive Polyacrylonitrile based Hydrogel for Heavy Metals Removal," no. 1, pp. 283-291, 2020, doi: 10.35940/ijrte.A1451.059120.

[35] B. Taşdelen, "Preparation and characterization of conducting hydrogels composite made of polyaniline, polyacrylamide and kaolin," Mater. Today Proc., vol. 5, no. 8, pp. 1598315989, 2018, doi: 10.1016/j.matpr.2018.05.042.

[36] M. H. Sorour, M. M. El Sayed, N. M. Abd El Moneem, H. A. Talaat, H. F. Shaalan, and S. M. El Marsafy, "Process and financial considerations pertinent to hydrogel manufacture," Starch/Staerke, vol. 65, no. 5-6, pp. 527-534, 2013, doi: 10.1002/star.201200181.

[37] M. H. Morcali and B. Zeytuncu, "Investigation of adsorption parameters for platinum and palladium onto a modified polyacrylonitrile-based sorbent," Int. J. Miner. Process., vol. 137, pp. 52-58, 2015, doi: 10.1016/j.minpro.2015.02.011.

[38] S. Cetiner, S. Sirin, M. Olariu, and A. S. Sarac, "Frequency and Temperature Dependence of Dielectric Behaviors for Conductive Acrylic Composites," Adv. Polym. Technol., vol. 35, no. 1, pp. 1-10, 2016, doi: 10.1002/adv.21523. 
[39] H. A. Patel et al., "High capacity carbon dioxide adsorption by inexpensive covalent organic polymers," J. Mater. Chem., vol. 22, no. 17, pp. 8431-8437, 2012, doi: 10.1039/c2jm30761h.

[40] L. Y. Wang and M. J. Wang, "Removal of Heavy Metal Ions by Poly(vinyl alcohol) and Carboxymethyl Cellulose Composite Hydrogels Prepared by a Freeze-Thaw Method," ACS Sustain. Chem. Eng., vol. 4, no. 5, pp. 2830-2837, 2016, doi: 10.1021/acssuschemeng.6b00336. 
Figures

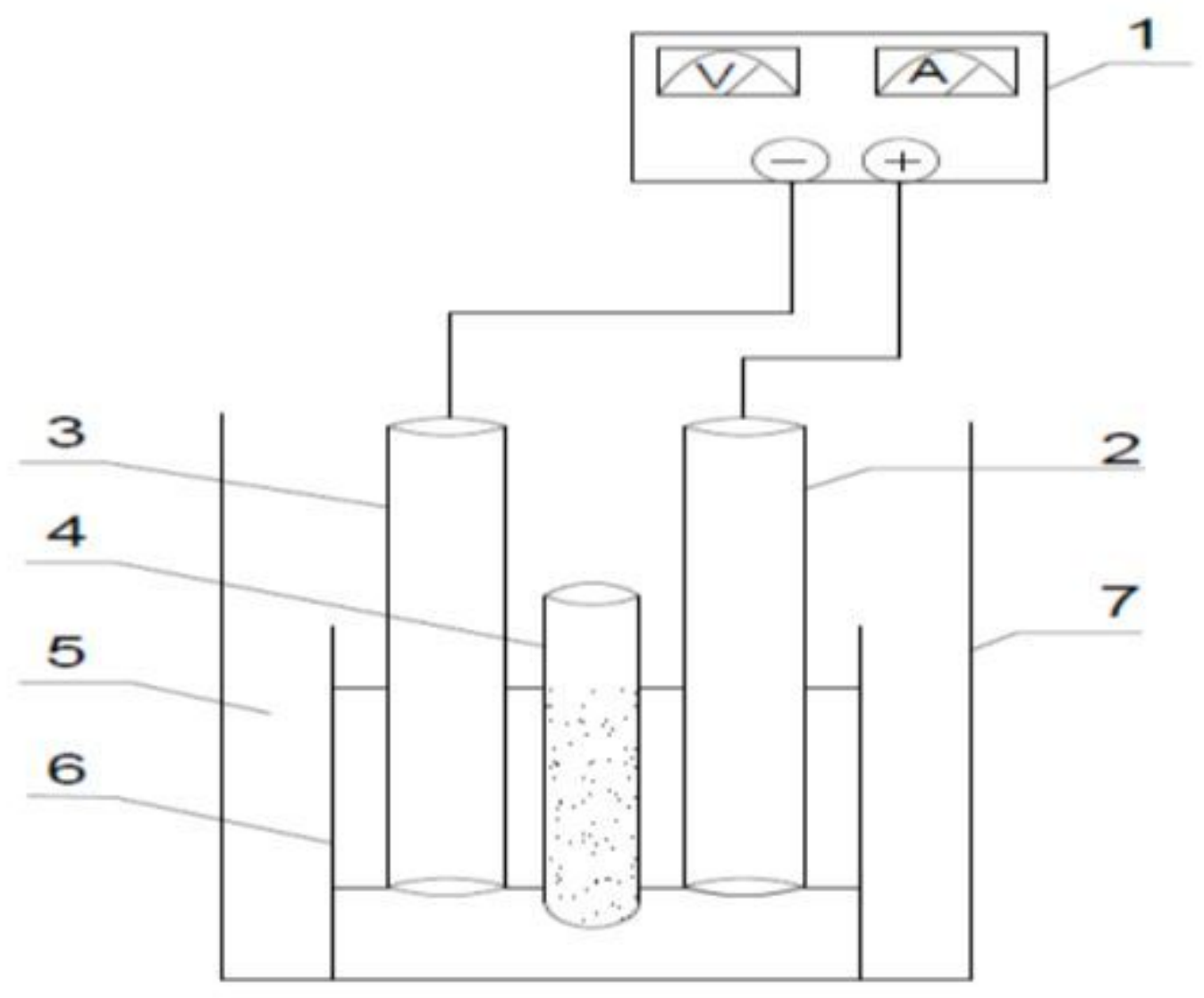

Figure 1

The electrically-assisted chemical regeneration system setup (i.e.; 1: DC power supply, 2: anodic electrode, 3: cathodic electrode, 4: plastic porous tube, 5: electrolyte, 6: three holes' holder, and 7: cell body). 


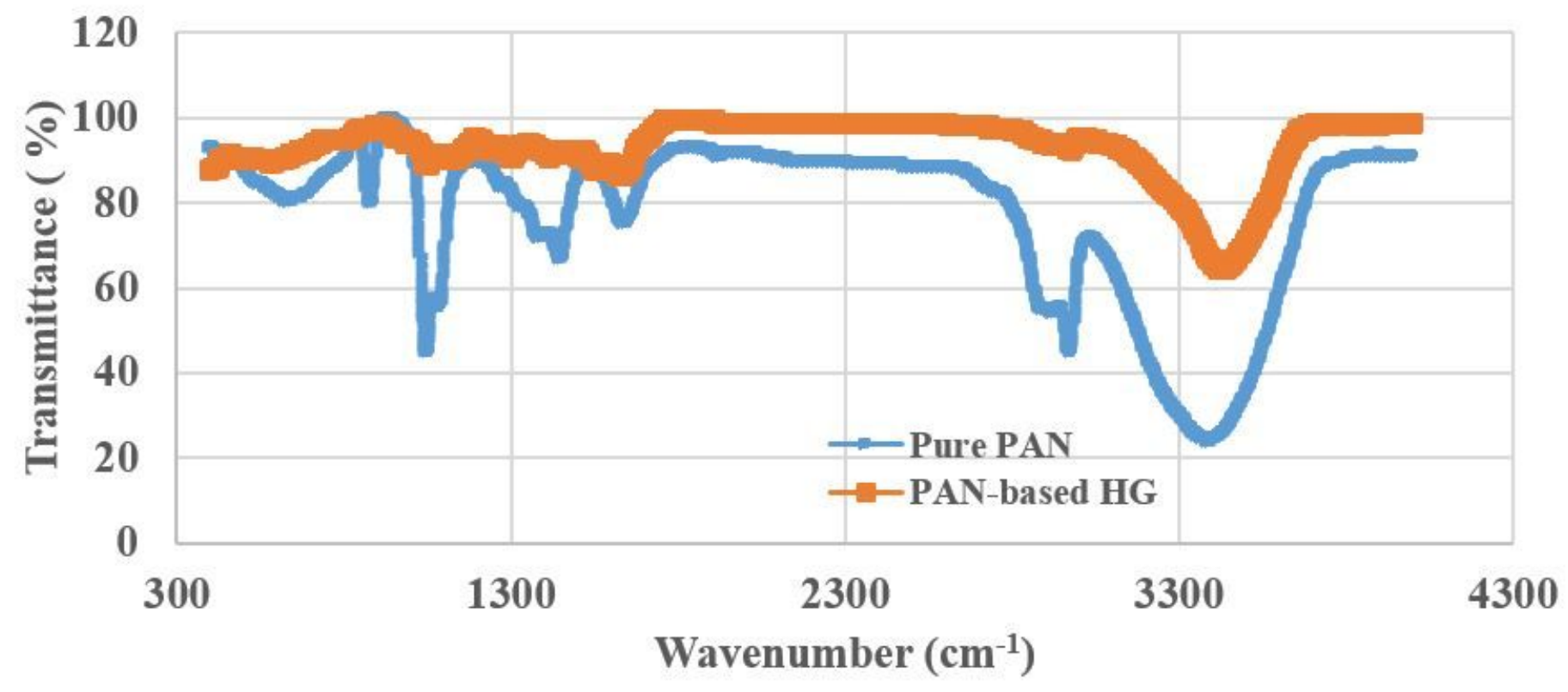

Figure 2

Infrared Spectrum (FTIR) of pure PAN, and the PAN-based HG .

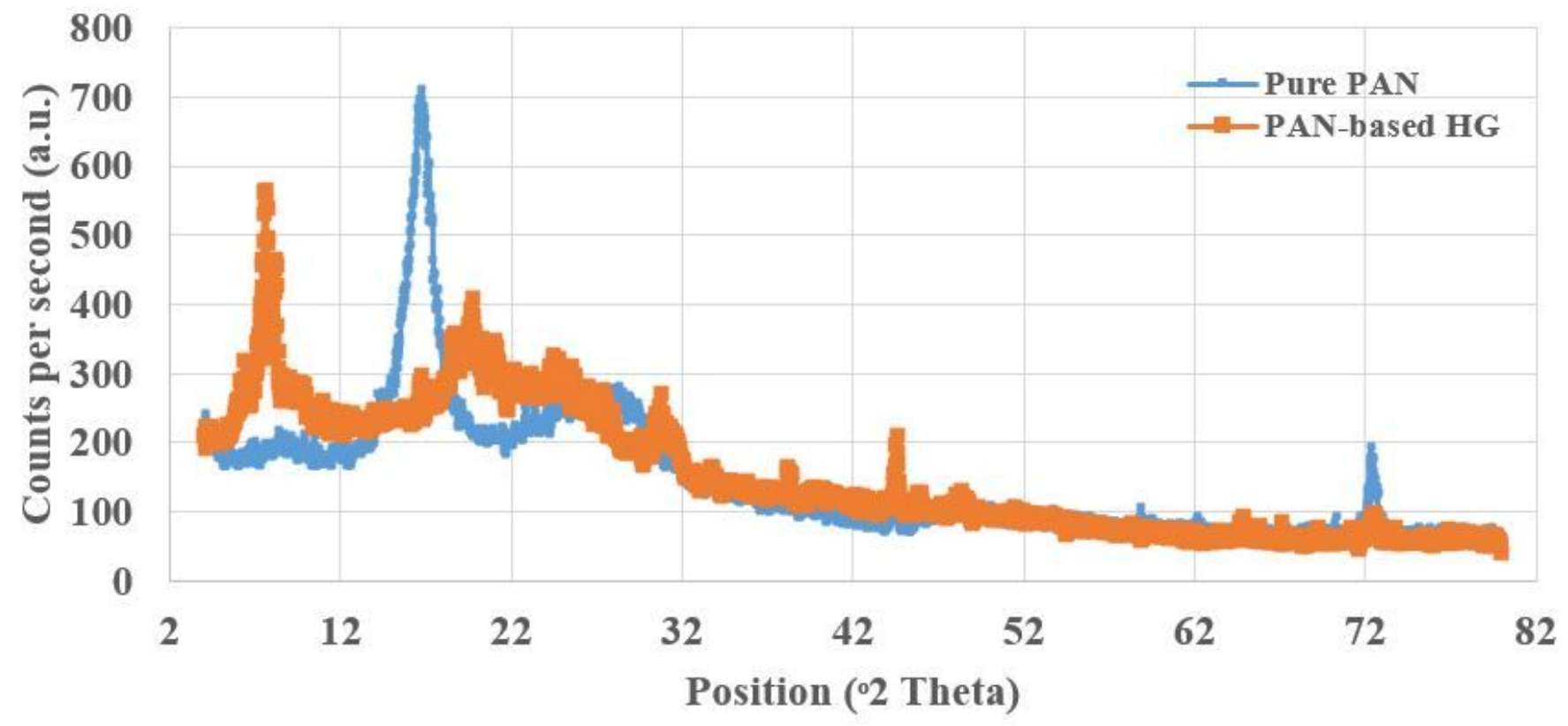

Figure 3

X-Ray diffraction for pure PAN, and the PAN-based HG. 


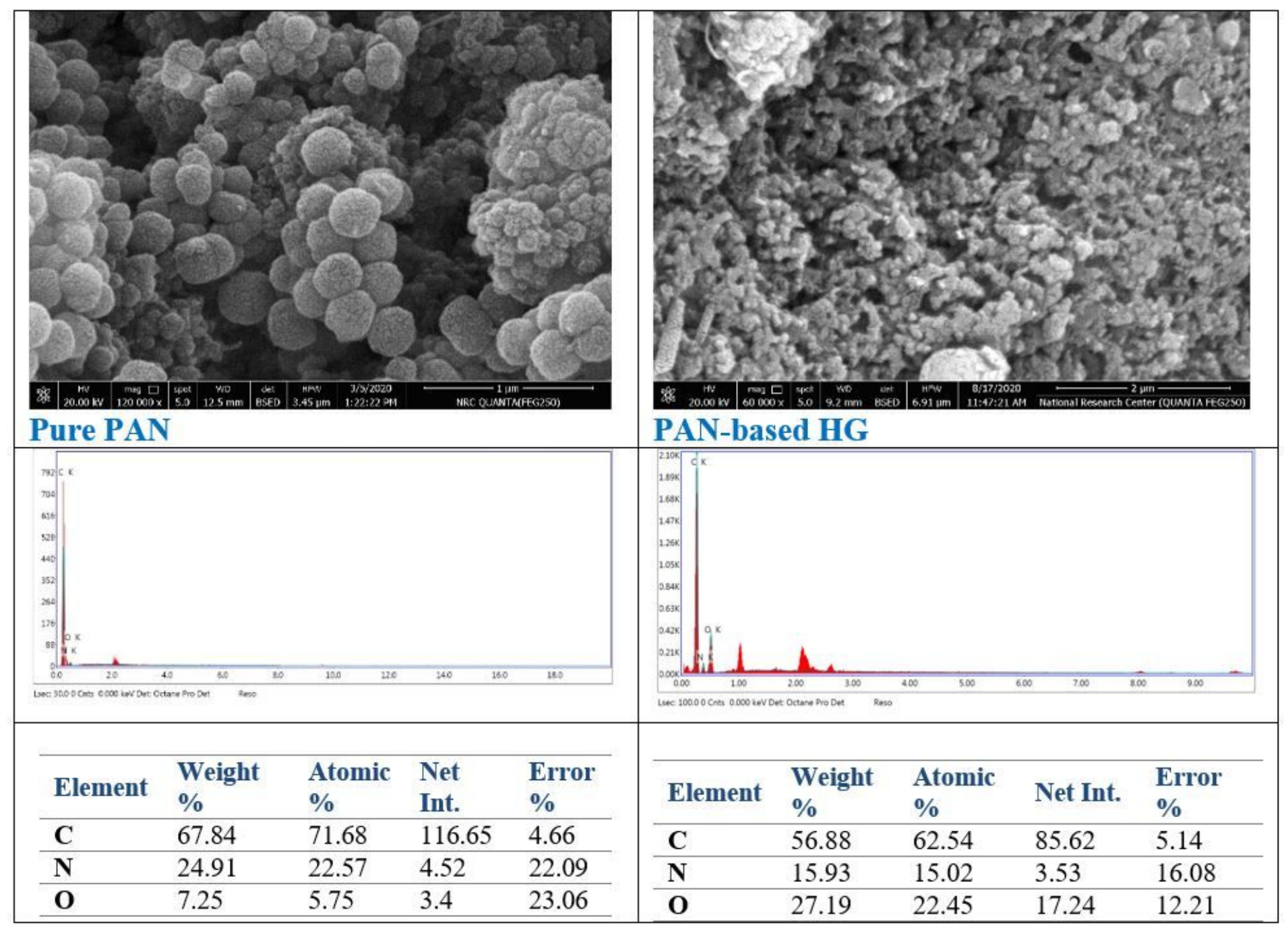

Figure 4

Scanning Electron Microscope (SEM) and their EDX data for pure PAN, and the PAN-based HG with $1 \mu$ m, and $2 \mu \mathrm{m}$, respectively 


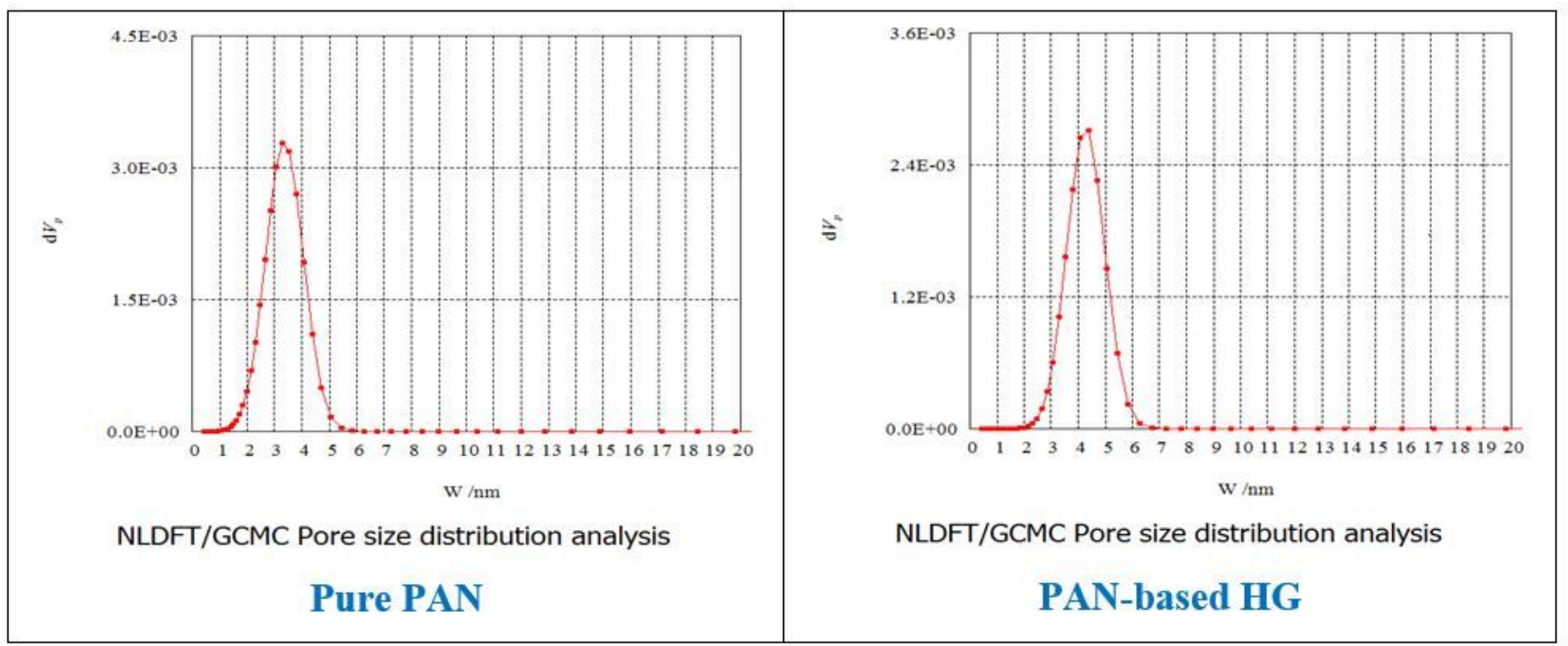

\section{Figure 5}

Pore size distribution analysis for pure PAN, and the PAN-based HG.

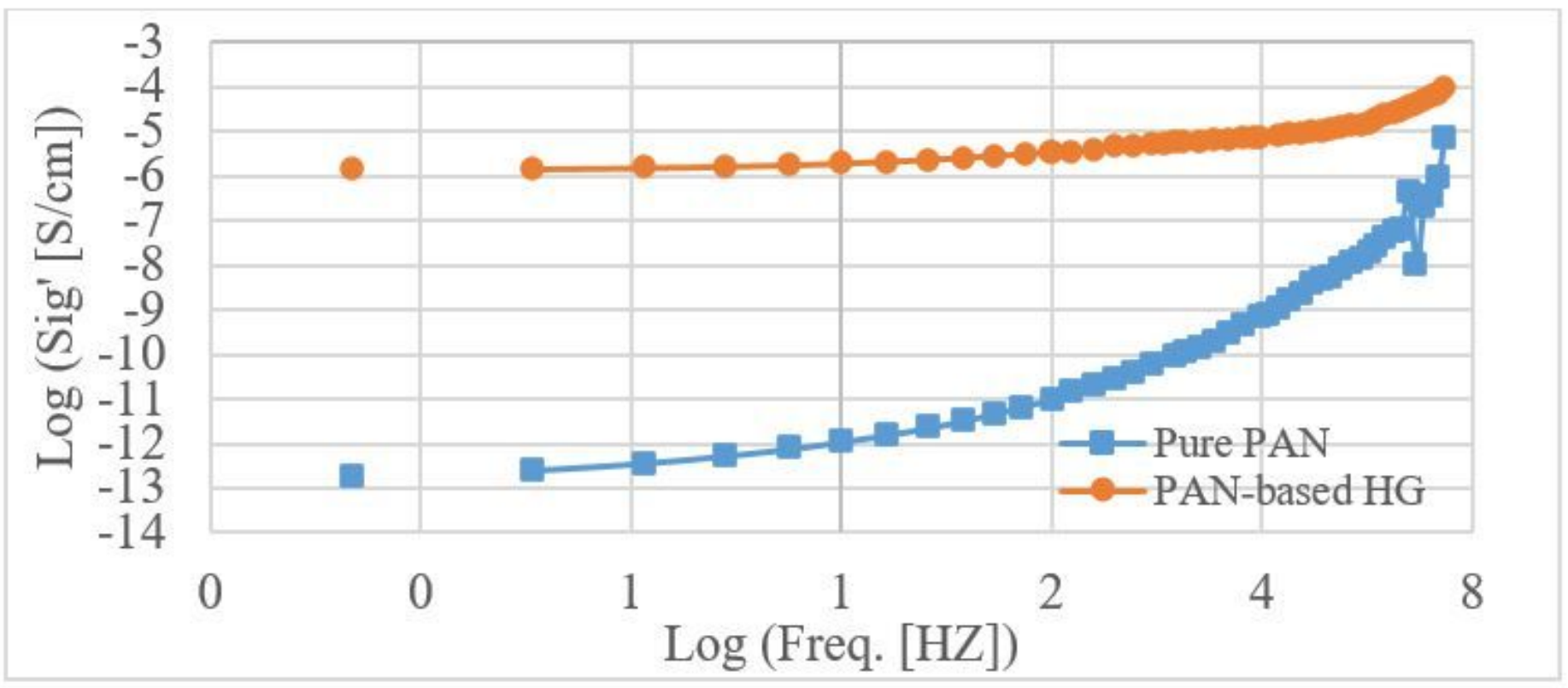

Figure 6

The conductivity for pure PAN, and the PAN-based HG . 


\section{Chromium Langmuir model}

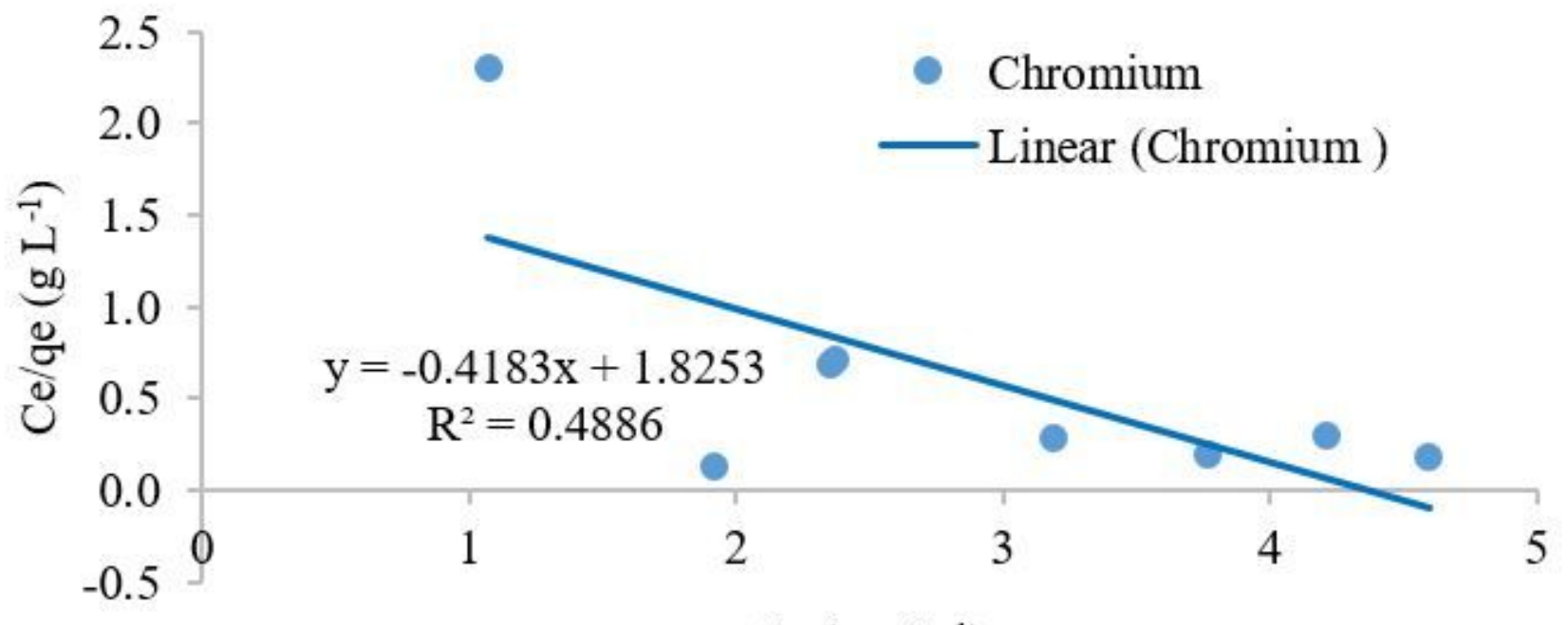

$\mathrm{Ce}\left(\mathrm{mg} \mathrm{L}^{-1}\right)$

Figure 7

Langmuir adsorption isotherm for chromium (i.e., qe: amount of adsorbate in the adsorbent at equilibrium (mg/g), and Ce: equilibrium concentration $(\mathrm{mg} / \mathrm{L})$ ).

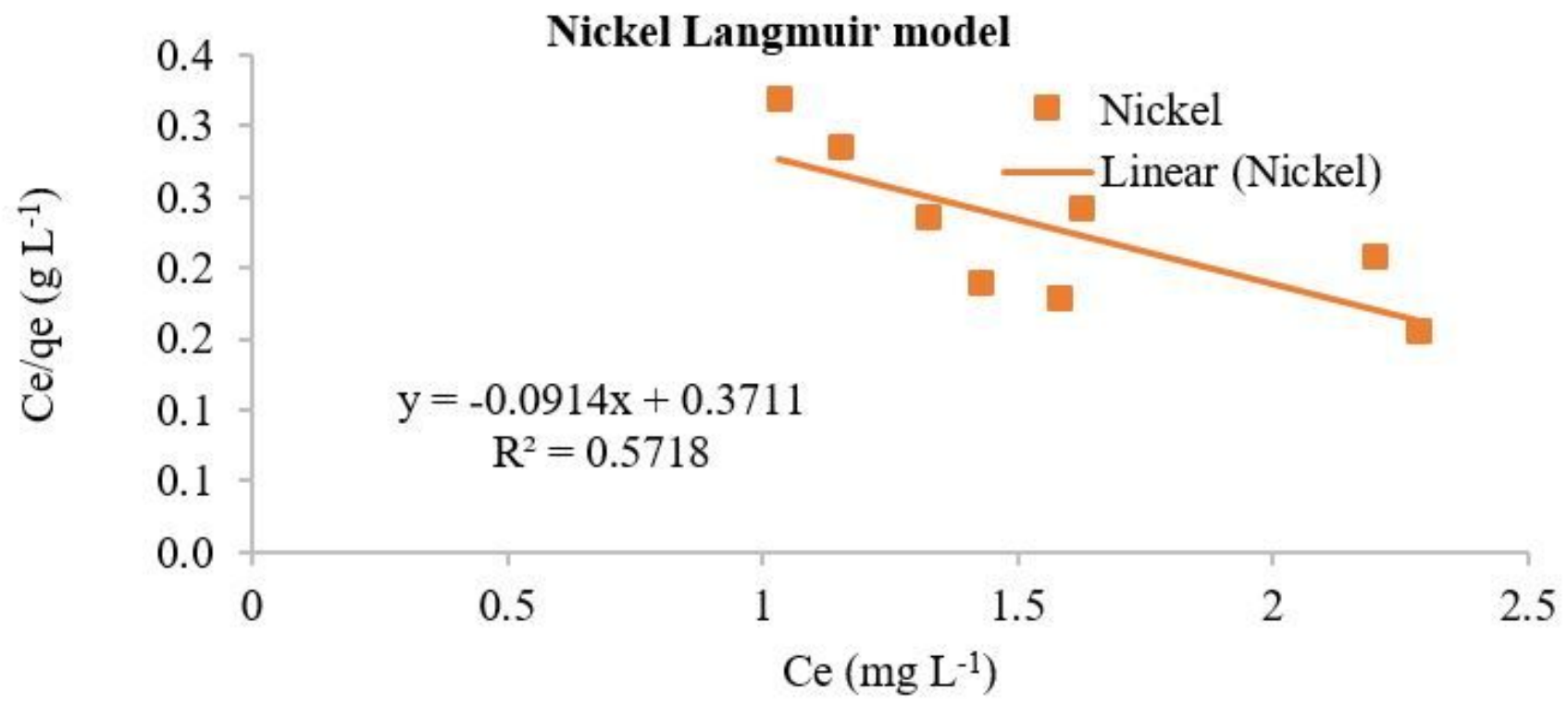

Figure 8 
Langmuir adsorption isotherm for nickel (i.e., qe: amount of adsorbate in the adsorbent at equilibrium $(\mathrm{mg} / \mathrm{g})$, and Ce: equilibrium concentration $(\mathrm{mg} / \mathrm{L})$ ).

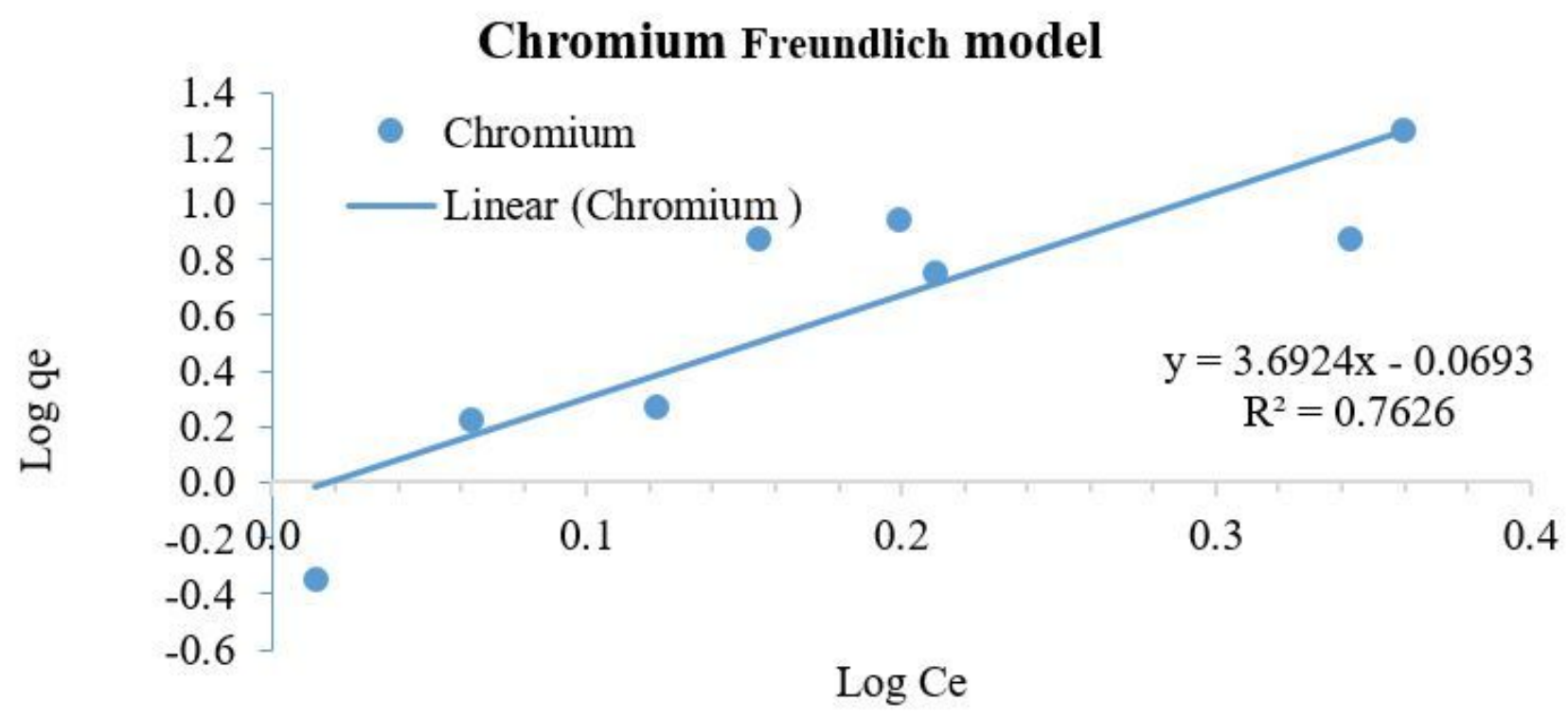

Figure 9

Freundlich adsorption isotherm for chromium (i.e., qe: amount of adsorbate in the adsorbent at equilibrium (mg/g), and Ce: equilibrium concentration (mg/L)).

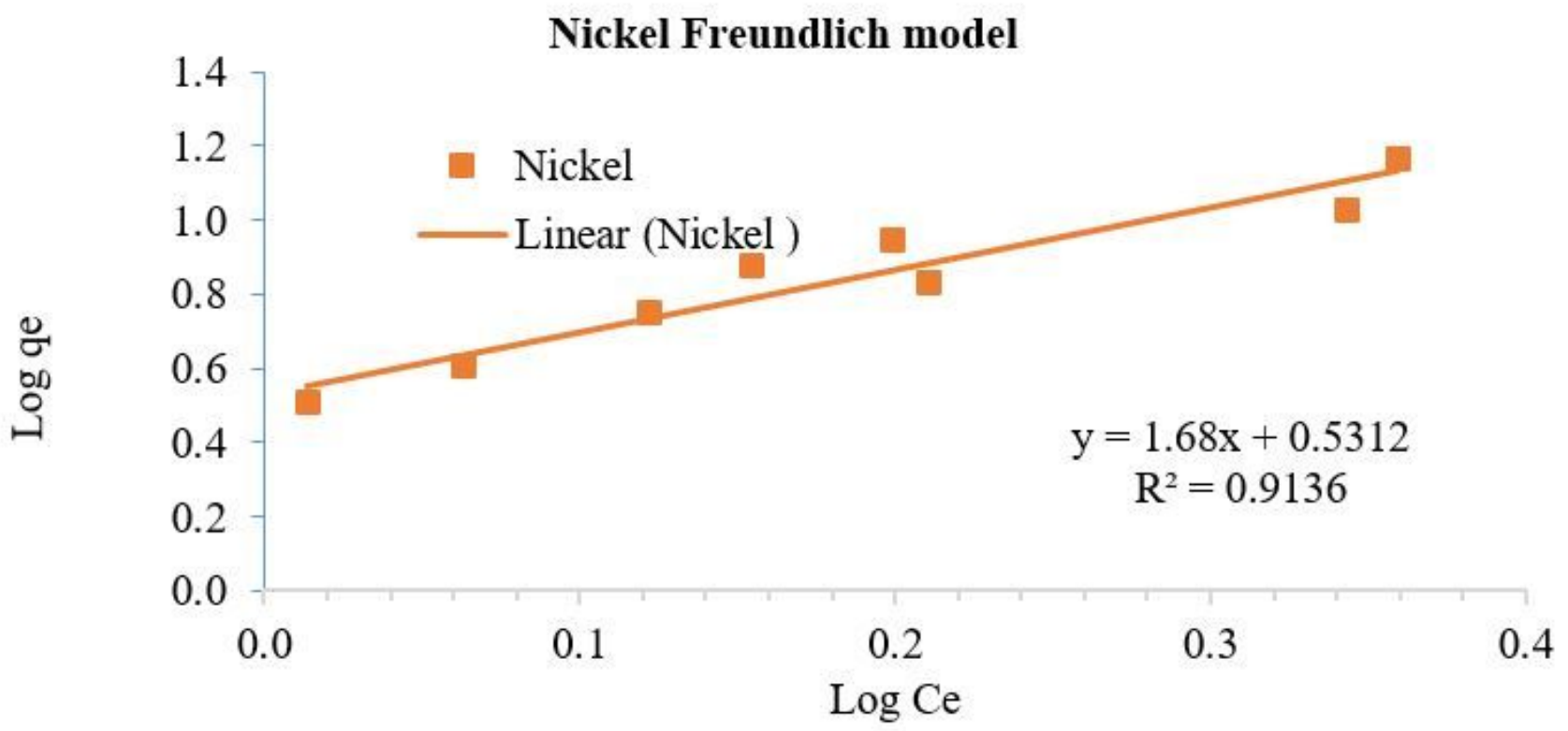

Figure 10 
Freundlich adsorption isotherm for nickel (i.e., qe: amount of adsorbate in the adsorbent at equilibrium $(\mathrm{mg} / \mathrm{g})$, and Ce: equilibrium concentration $(\mathrm{mg} / \mathrm{L})$ ).

\section{Chromium Pseudo First order (PFO) model}

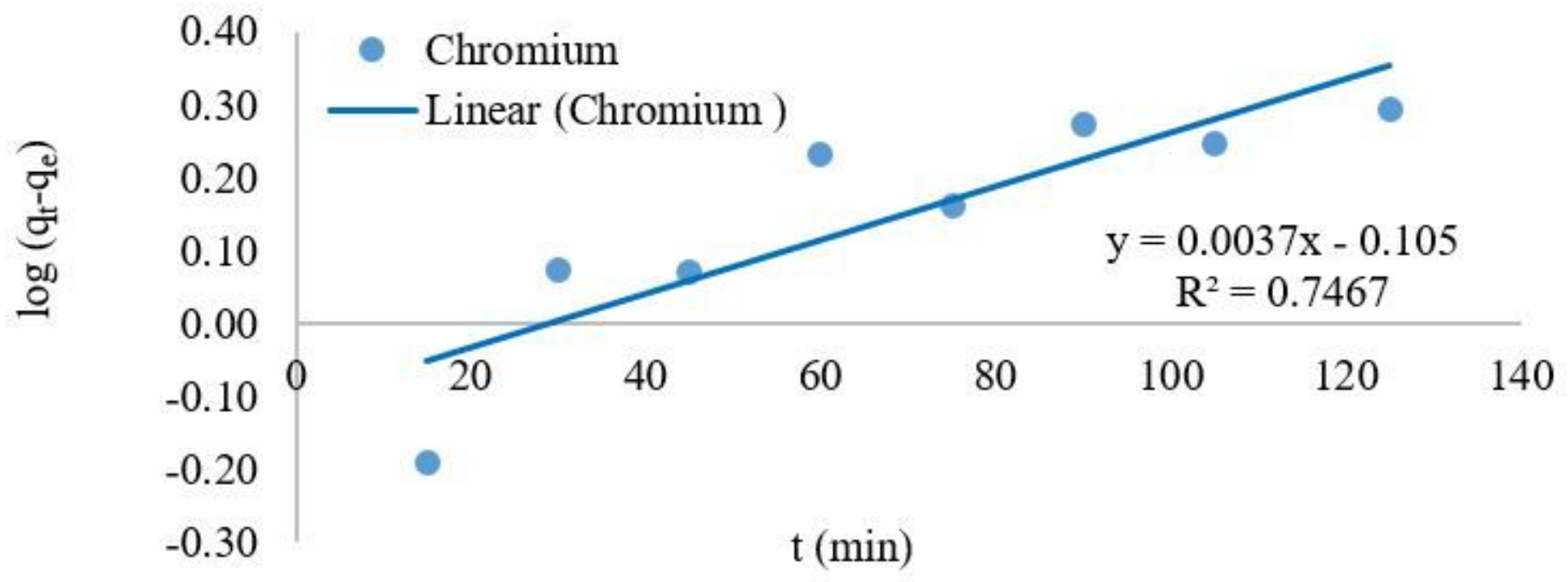

Figure 11

Pseudo first order (PSO) kinetic modeling for chromium.

\section{Nickel Pseudo First order (PFO) model}

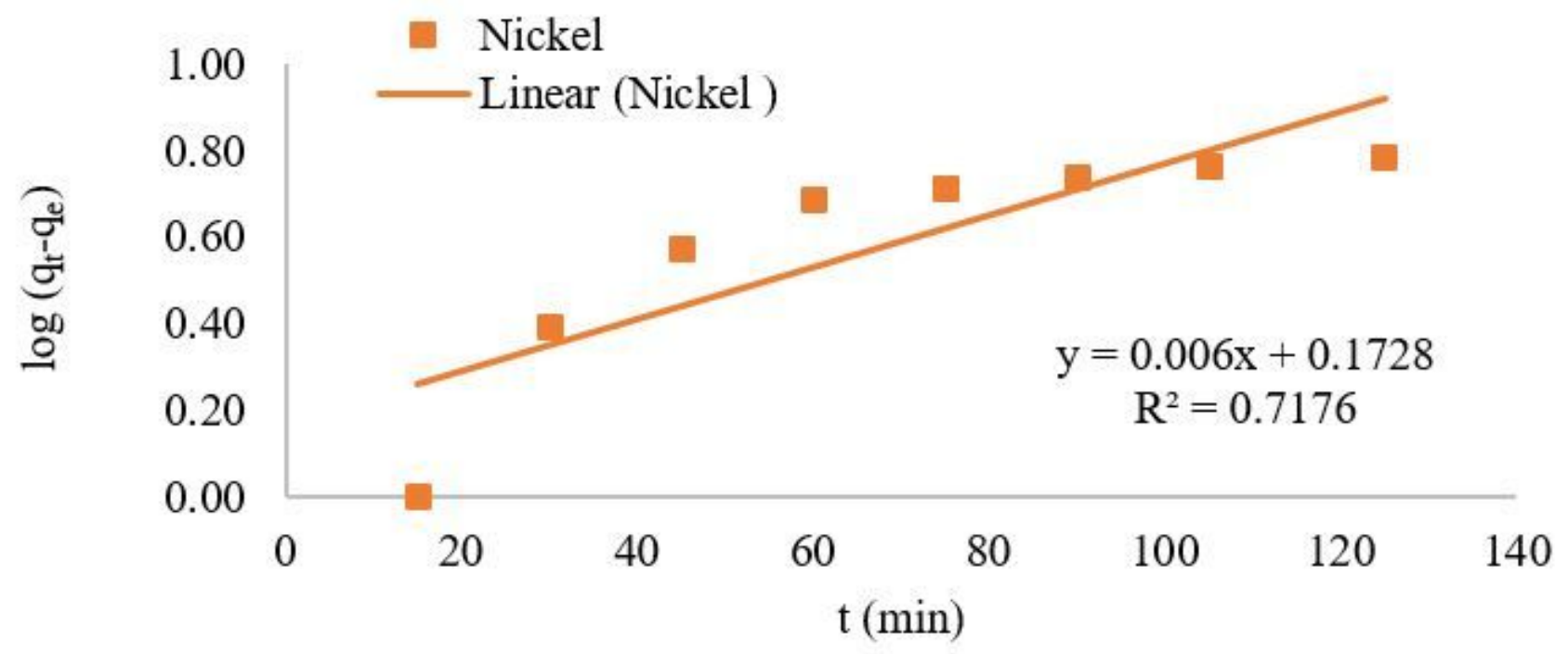

Figure 12

Pseudo first order (PSO) kinetic modeling for nickel. 


\section{Chromium Pseudo second order (PSO) model}

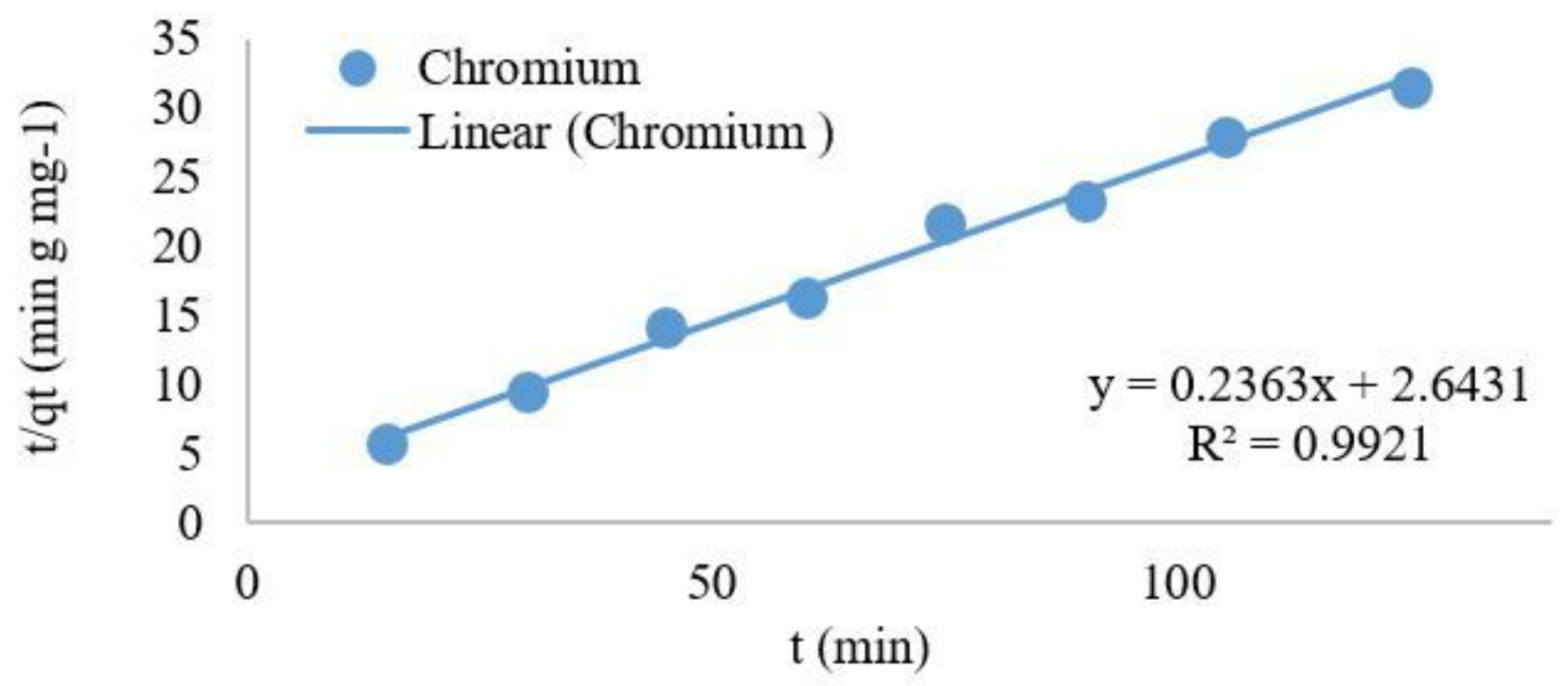

Figure 13

Pseudo second order (PSO) kinetic modeling for chromium.

\section{Nickel Pseudo second order (PSO) model}

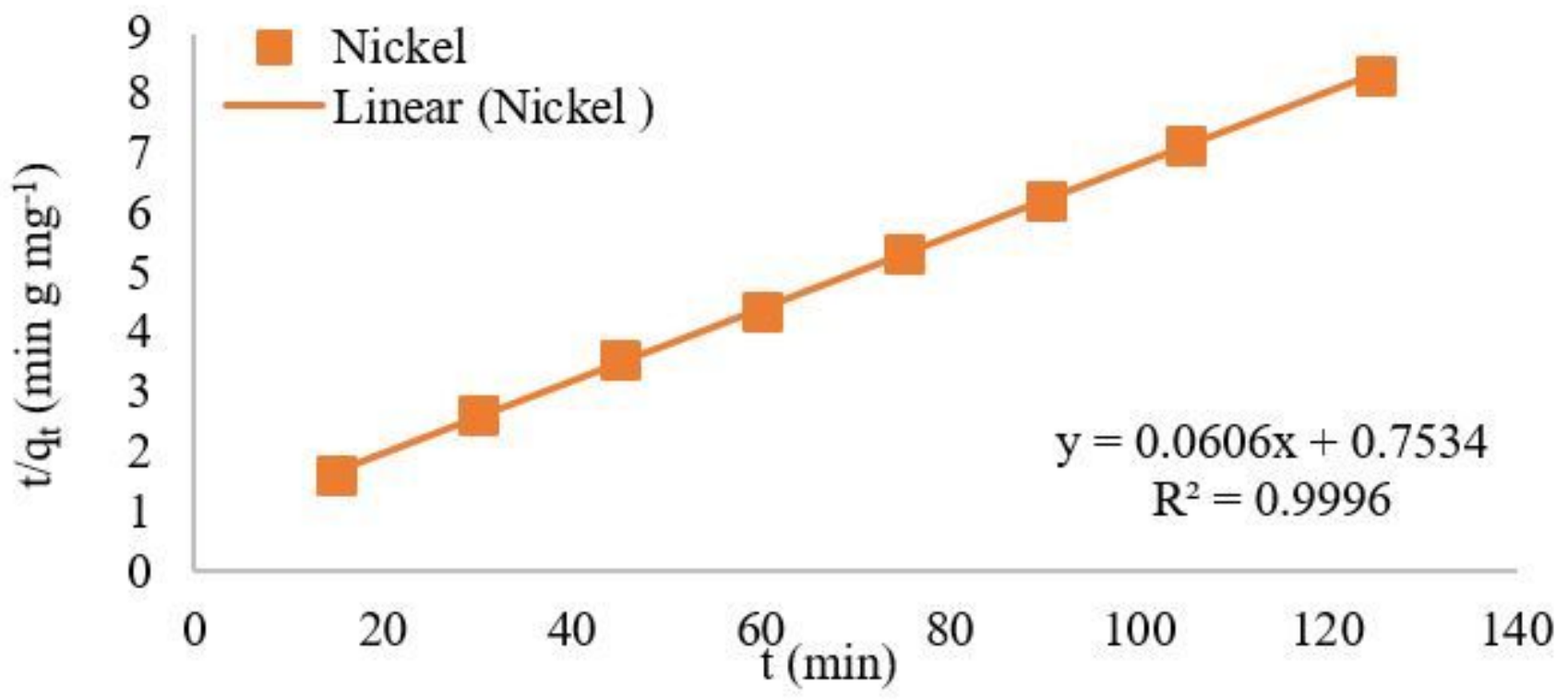

Figure 14

Pseudo second order (PSO) kinetic modeling for nickel. 


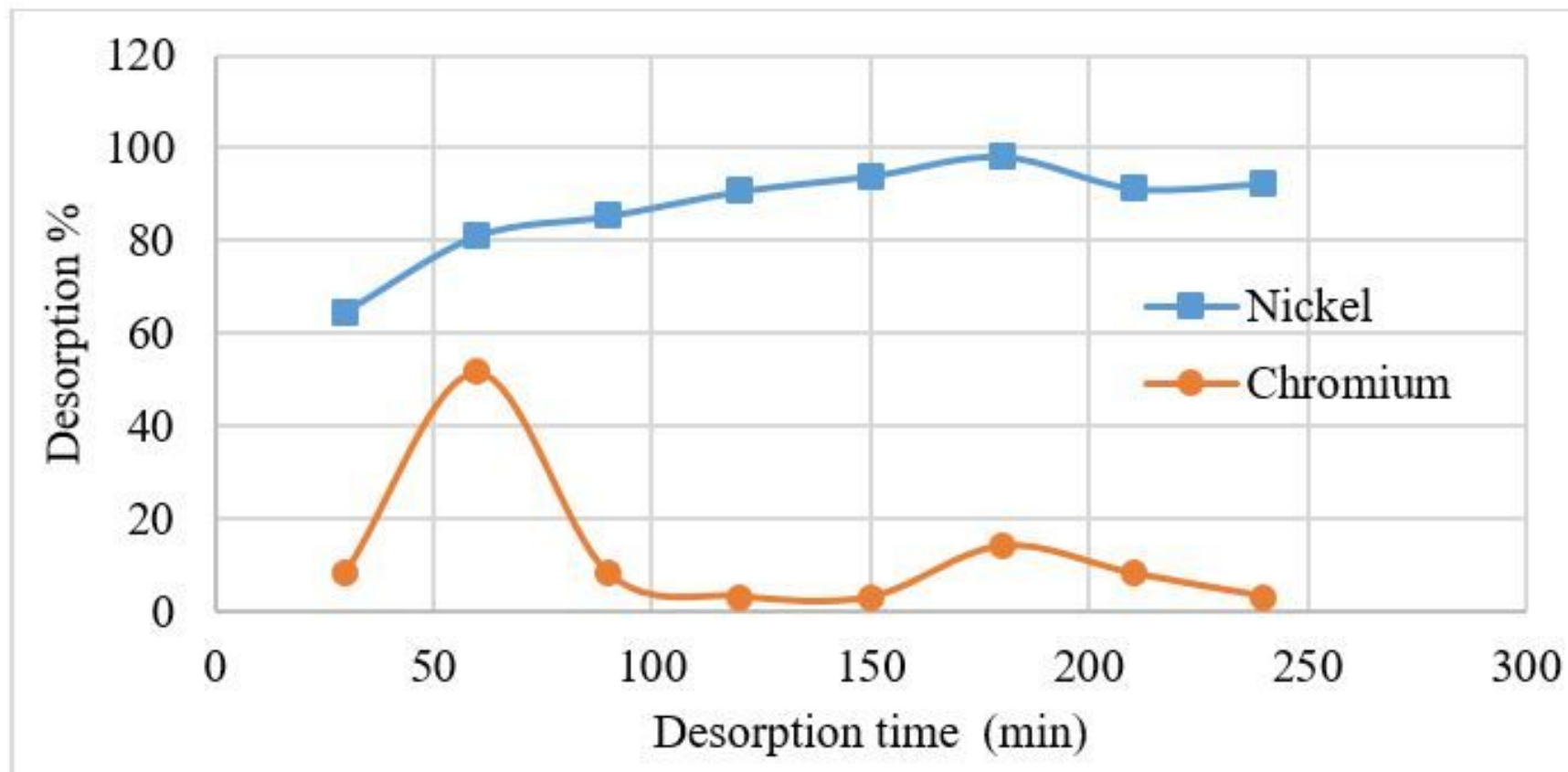

Figure 15

The desorption percentage values with time for chromium and nickel.

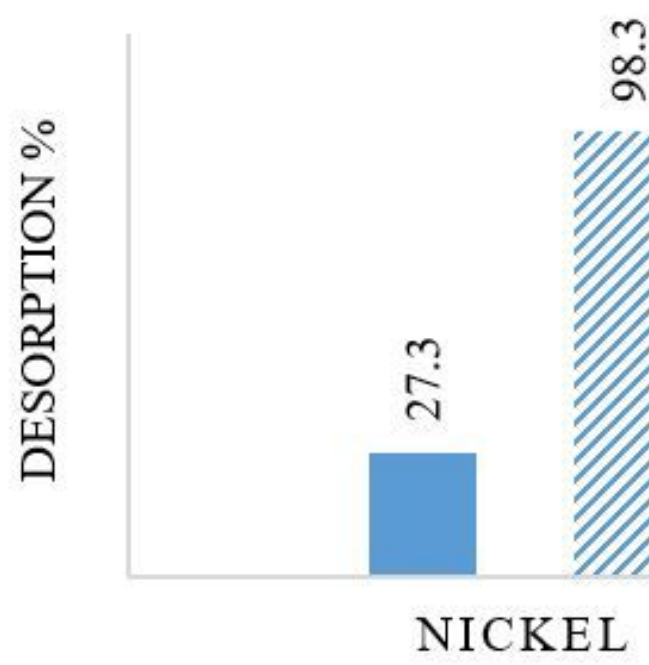

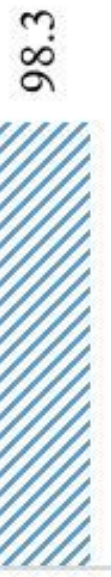

NICKEL
Chemically

/. Electrochemically

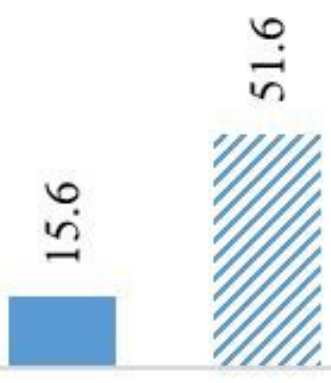

CHROMIUM

\section{SALT}

\section{Figure 16}

The desorption percentage values for chromium and nickel chemically and electrochemically. 